\title{
The chemistry of the massive outflow source G5.89-0.39
}

\section{A $330-360 \mathrm{GHz}$ molecular line survey}

\author{
M.A. Thompson and G.H. Macdonald \\ Electronic Engineering Laboratory, University of Kent, Canterbury, Kent, CT2 7NT, UK
}

Received October 15; accepted November 27, 1998

\begin{abstract}
We have performed a $330-360 \mathrm{GHz}$ molecular line survey of the molecular gas associated with the ultracompact (UC) HII region G5.89-0.39. 142 lines originating from 19 species were detected and a further 6 lines that could not be identified. Over $50 \%$ of the identified molecular lines are from sulphur-bearing species, with $\mathrm{SO}_{2}$ (and its isotopomer ${ }^{34} \mathrm{SO}_{2}$ ) exhibiting the most lines. No emission from heavy organic molecules (e.g. dimethyl ether, ethanol, methyl formate) was detected. The lines can be divided into two types by their profiles: narrow lines with no (or slight) wing emission which probe a molecular envelope surrounding the UC HII region and broad lines with considerable wings which may probe the gas in the bipolar molecular outflow associated with the UC HII region. We discuss the chemical models which may explain the features observed in the survey and outline the strategy for the chemical modelling of the evolution of the molecular gas, to be considered more quantatively in a following paper.
\end{abstract}

Key words: ISM: individual objects: G5.89-0.39 ISM: molecules — ISM: jets and outflows — line: identification - ISM: abundances — radis lines: ISM

\section{Introduction}

Outflows play a fundamental role in star formation. Excess angular momentum in the protostellar system is removed by the outflow, the star-forming core of dust and gas is disrupted by the outflow, possibly limiting the mass of the resulting star, and the interaction of the outflow with the natal molecular cloud may have far-reaching effects on subsequent star formation within the cloud.

Outflows from low mass young stellar objects (YSOs) have been well studied to date; for example the reviews by Bachiller (1996) and Fukui (1993) and references therein. Molecular outflows and high-velocity ionised jets have

Send offprint requests to: G.H. Macdonald been observed toward low mass YSOs. The molecular outflows are thought to be driven by the jets, with the momentum from the jet transferred to the molecular material by entrainment (either prompt entrainment by bow shocks at the head of the jet or steady state entrainment by turbulent mixing along the sides of the jet, De Young 1986). There is a strong relationship between the mechanical force and luminosity of the molecular outflow and the bolometric luminosity, particularly the $6 \mathrm{~cm}$ continuum emission (Cabrit \& Bertout 1992) of the central protostar driving the outflow, which suggests a close association between ionised and molecular gas. The driving force behind the bipolar ionised jets is not yet clear. Current theories suggest the jets are wind-driven, possibly by either a disc-collimated wind (Pelletier \& Pudritz 1992) or from boundary layer effects in the protostellar accretion disc (Shu et al. 1995).

The overall picture of massive YSO outflows is much less certain. The large distance of most high mass star forming regions makes it difficult to resolve fine detail and the higher degree of turbulence present in massive star forming cores confuses the location of high-velocity emission from outflows. It is important though to determine the properties of massive YSO outflows to place them in the context of the models developed for low mass YSO outflows and to test the predictions of the models against the properties of high mass YSO outflows. Until recently only a few isolated examples of massive stellar outflows were known (e.g. G5.89-0.39, DR 21 and G45.12). Studies by Shepherd \& Churchwell (1996a,b) have revealed high velocity CO emission present in $90 \%$ of a survey of massive YSOs and have determined the properties of five outflows by mapping a sample of sources with high velocity emission from the survey.

One of the most important aspects of this recent work on massive YSO outflows has been the confirmation that massive YSO outflows lie at the more extreme end of the scale. The mass contained in massive YSO outflows is at least an order of magnitude higher than that of most YSO 
outflows. The flow rates of massive YSO outflows are also in general larger than their low mass counterparts. If both outflow phenomena share a common origin, massive YSO outflows thus represent an ideal test of the models developed for low mass YSO outflows. Doubts have been raised whether disc-collimated wind or boundary-layer (so-called $\mathrm{X}$-wind models) models of outflows are capable of driving the large masses in massive YSO outflows (Churchwell 1997), although the massive bipolar outflow associated with G192.16 exhibits properties of both disc-collimated and X-wind models (Shepherd et al. 1998). Further studies of massive YSO ouflows are necessary to determine whether high and low mass protostars share a common outflow mechanism.

The chemistry in massive and low mass YSO outflows is presumably driven by a common process. Outflows drive shocks into the ambient molecular gas and strongly affect the chemistry. The chemistry is altered by both the heating action of the shock which permits reactions with high activation energies to take place and by the injection of disrupted grain mantles (and perhaps grain cores) into the gas phase. The most striking difference between quiescent cloud and shock-driven chemistry is in the abundance of $\mathrm{SiO}$, which is several orders of magnitude higher toward shocked regions (Schilke et al. 1997a). Other species, such as $\mathrm{SO}, \mathrm{NH}_{3}$ and $\mathrm{CH}_{3} \mathrm{OH}$ are also observed to have raised abundances toward outflows (Bachiller 1996 and references therein).

Molecular line surveys of low mass YSO outflows (e.g. Blake et al. 1995; Bachiller \& Perez-Gutierrez 1997) have been extremely useful in characterising the chemistry of the outflow and in deriving the physical parameters of the gas from the detected molecular lines. However as in the dynamical study of outflows the main effort has focussed on low mass YSO outflows. For this reason we have undertaken a $330-360 \mathrm{GHz}$ molecular line survey of the massive YSO outflow associated with G5.89-0.39. The outflow is compact, the lobes are separated by $\sim 6^{\prime \prime}$ as traced in $\mathrm{SiO}$ emission, and massive with an outflowing mass of $\sim 80$ solar masses (Harvey \& Forveille 1988; Acord et al. 1997). There is also a dense envelope of dust (Harvey et al. 1994) and molecular gas (Gomez et al. 1991) surrounding the UC HII region, which is the prototypical example of the shell morphology (Wood \& Churchwell 1989).

The compactness of the outflow means that both lobes and the envelope gas associated with the UC HII region can be sampled in a single $13^{\prime \prime}$ HPBW observation. The line profiles can be used to determine whether emission arises predominantly from the envelope gas located close to the UC HII region or from within the accelerated gas of the outflow. Turbulence within the envelope, observed to be fairly ubiquitous towards regions of massive star formation (Plume et al. 1997), will confuse the issue although the line profiles of particular species will indicate species that can be explored further with higher resolution interferometric observations.
The HII region G5.89-0.39 is also postulated to be young from observations of its expansion rate (Acord et al. 1998) and the high dust density in the immediate environment (Harvey et al. 1994). We will be able to contrast the results of the $330-360 \mathrm{GHz}$ survey with other recent molecular line surveys of G34.26 (Macdonald et al. 1996) and Orion-KL (Schilke et al. 1997b), in order to test the hypothesis that the chemistry of these objects can be used as a "chemical clock" to date the evolution of the molecular gas.

In summary, the aims of this survey are: (1) to characterise the chemistry of the molecular gas associated with G5.89-0.39, (2) to identify species located within the outflow by their high velocity line wings, (3) to derive the physical parameters of the molecular gas and (4) to examine whether hot core or shock-driven chemical models can reproduce the observed column densities. Parts (1) and (2) are presented in this paper, along with a first approach to part (3) by deriving the rotational temperatures and column densities of those species with sufficient detected transitions. A more detailed physical analysis and chemical modelling (parts 3 and 4) will be contained in the forthcoming Paper II.

The observations and data reduction procedure are detailed in the next section. The identified lines, inspection of their profiles for high velocity emission and rotation diagrams are presented in Sect. 3. The implications of the survey are discussed in Sect. 4 with particular reference to shock-driven and hot core chemical models.

\section{Observations and data reduction}

\subsection{Observations}

The observations were made with the James Clerk Maxwell Telescope (JCMT) ${ }^{1}$ between the 8 th and 14 th March 1996. All observations were made at the coordinates $\alpha(1950)=17^{\mathrm{h}} 57^{\mathrm{m}} 27^{\mathrm{s}}$ and $\delta(1950)=-24^{\circ} 03^{\prime} 57^{\prime \prime}$, which is the estimated centre of the UC HII region (Wood \& Churchwell 1989). The pointing accuracy of the telescope was checked regularly against the peak continuum position of the UC HII region G34.26+0.15 and was found to be good to within $5^{\prime \prime}$. It was found that beam-switching (i.e. chopping the secondary mirror from on-source to offsource) was much superior to position switching for obtaining extremely flat baselines. A chop throw of $3^{\prime}$ in RA was used to keep a constant reference position, with a chopping frequency of $1 \mathrm{~Hz} .3^{\prime}$ was more than sufficient to avoid contamination in the reference position for all species except CO (as can be seen in Fig. 1).

1 The JCMT is operated by the Royal Observatories on behalf of the Particle Physics and Astronomy Research Council of the UK, the Netherlands Organisation for Scientific Research and the National Research Council of Canada. 

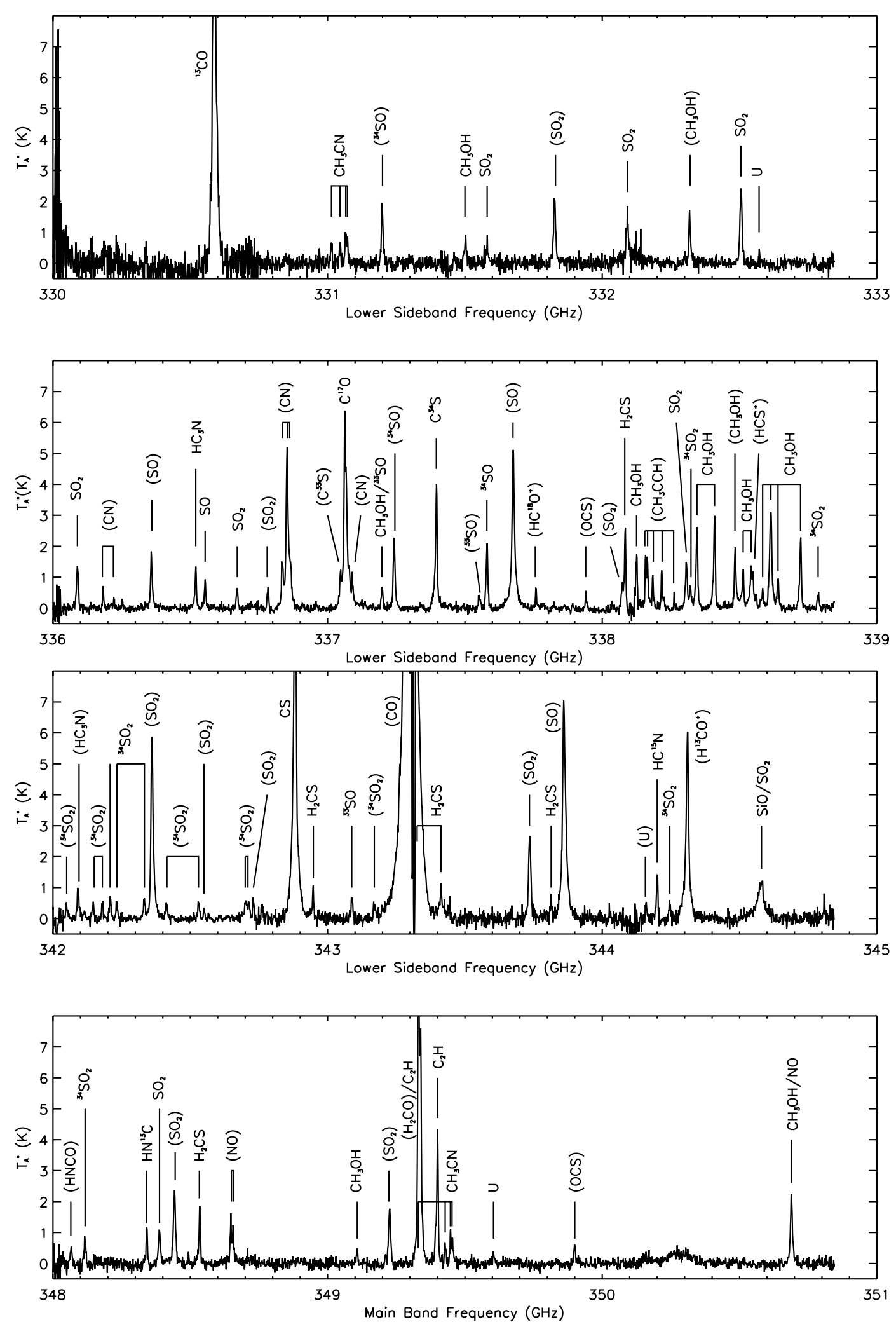

Fig. 1. Spectra observed during the $330-360 \mathrm{GHz}$ survey of G5.89-0.39. The frequency scale given for each block of spectra is the lower sideband scale, the upper sideband scale is omitted as it is not continuous for the blocks of concatenated spectra. Species identifications are shown for each line and upper sideband lines are indicated by brackets 


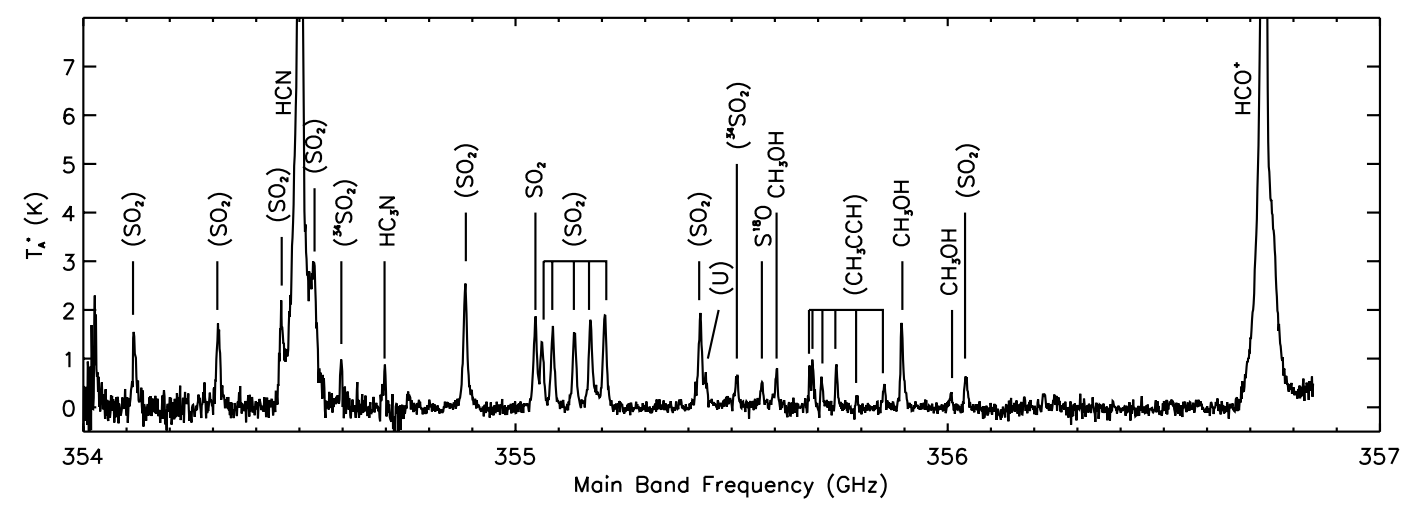

Fig. 1. continued

To cover the frequency range of the survey the $345 \mathrm{GHz}$ SIS junction receiver B3i (RxB3i) was used in conjunction with the Dutch Autocorrelation Spectrometer (DAS). The DAS was used in $760 \mathrm{MHz}$ bandwidth mode and with $\mathrm{RxB} 3 \mathrm{i}$ as a frontend produces dual sideband spectra. Dual sideband spectra comprise two frequency bands (the upper and lower sidebands) folded over one another to produce a composite spectra. The upper and lower sidebands are separated in frequency by approximately twice the local oscillator intermediate frequency (IF), depending on the doppler correction for the source velocity. The upper sideband frequency scale is reversed relative to the lower sideband scale. The velocity of G5.89-0.39 with respect to the Local Standard of Rest $\left(V_{\mathrm{LSR}}\right)$ was assumed to be $+9.4 \mathrm{~km} \mathrm{~s}^{-1}$. For RxB3i the IF is $1.5 \mathrm{GHz}$ and the upper and lower sidebands are separated by approximately $3 \mathrm{GHz}$. Each spectrum taken thus represents a total frequency range of $\sim 1.5 \mathrm{GHz}$ and this was used to reduce the total number of spectra needed to cover the frequency range of the survey.

The spectra were all observed with the "main band" set to the lower sideband, which means that the other (upper) sideband covers a frequency range of the same width roughly $3 \mathrm{GHz}$ higher in frequency. We took spectra with their central frequency incremented by $700 \mathrm{MHz}$ (ensuring an overlap of $30 \mathrm{MHz}$ between spectra) until the lower sideband had covered the first $2.8 \mathrm{GHz}$ of the frequency range. The upper sidebands of these spectra cover the next $2.8 \mathrm{GHz}$ of the frequency range with a $200 \mathrm{MHz}$ gap in coverage. This block of 4 spectra thus covers a total frequency range of $5.6 \mathrm{GHz}$. The remaining parts of the frequency range were observed in the same manner. The $200 \mathrm{MHz}$ gaps between the blocks of spectra were to be covered by additional spectra taken at the end of the observing run, however due to bad weather this was not achieved. These gaps do not contain many lines of significance; searches of spectral line catalogues (both of predicted and observed lines) indicate that few lines occur in these frequency ranges. The blocks of spectra (with individual spectra concatenated) are shown in Fig. 1.
Two problems inherent in dual sideband spectra are the allocation of features to a particular sideband (i.e. upper or lower) and the possible overlapping (blending) of lines from each sideband. To determine the sidebands (and hence line frequencies) extra spectra with a local oscillator shift of $+10 \mathrm{MHz}$ were taken. In the shifted spectra lines in the upper sideband will appear to shift frequency by $20 \mathrm{MHz}$ relative to those in the lower sideband. Blended lines from both sidebands were separated by this technique whenever possible.

With the DAS in $760 \mathrm{MHz}$ mode the spectral resolution is $0.756 \mathrm{MHz}$. Each spectrum was divided into channels of $0.625 \mathrm{MHz}$, although later in the data reduction process all spectra were binned to a channel width of $1.25 \mathrm{MHz}$ to improve signal to noise. The standard chopper-wheel calibration method of Kutner \& Ulich (1981) was used to obtain line temperatures on the $T_{\mathrm{A}}^{*}$ scale, i.e. corrected for the atmosphere, resistive telescope losses and rearward spillover and scattering. $T_{\mathrm{A}}^{*}$ can also be corrected for forward spillover and scattering to give the corrected receiver temperature $T_{\mathrm{R}}^{*}$ where $T_{\mathrm{R}}^{*}=T_{\mathrm{A}}^{*} / \eta_{\mathrm{fss}}$ and $\eta_{\mathrm{fss}}$ is the forward spillover and scattering efficiency ( 0.7 for RxB3i at $345 \mathrm{GHz}$ ).

\subsection{Data reduction and line identification}

The data were reduced using the Starlink spectral line package SPECX. Linear baselines were subtracted from the spectra and the line parameters of peak temperature $\left(T_{\mathrm{A}}^{*}\right)$, central frequency $(\nu(\mathrm{obs}))$ and line width at half maximum $\left(\Delta \nu_{1 / 2}\right)$ were measured. Values for the noise in the spectra were evaluated using line-free channels and the typical rms noise level was found to be $\sigma \sim 0.1 \mathrm{~K}$ at a spectral resolution of $1.25 \mathrm{MHz}$. Features below a detection limit of $5 \sigma$ were ignored to avoid inaccurate line identifications. These data are given in Table 5 for each line. Multiple independent detections of each line (i.e. including the $10 \mathrm{MHz}$ shifted spectra) are listed.

The identification of molecular lines detected in this survey was achieved by comparing their central frequencies primarily with the JPL spectral line database 
Table 1. Species (including isotopomers) identified in the survey. The identification of certain species from single line detections must however be regarded with caution

\begin{tabular}{|l|c|l|c|}
\hline Species & $\begin{array}{c}\text { Number of } \\
\text { detected lines }\end{array}$ & Species & $\begin{array}{c}\text { Number of } \\
\text { detected lines }\end{array}$ \\
\hline $\mathrm{CO}$ & 1 & $\mathrm{HCN}$ & 1 \\
${ }^{13} \mathrm{CO}$ & 1 & $\mathrm{HC}^{15} \mathrm{~N}$ & 1 \\
$\mathrm{C}^{17} \mathrm{O}$ & 1 & $\mathrm{HN}^{13} \mathrm{C}$ & 1 \\
$\mathrm{SO}$ & 5 & $\mathrm{HNCO}$ & 1 \\
${ }^{34} \mathrm{SO}$ & 3 & $\mathrm{NO}$ & 2 \\
${ }^{33} \mathrm{SO}$ & 3 & $\mathrm{HCO}^{+}$ & 1 \\
$\mathrm{~S}^{18} \mathrm{O}$ & 1 & $\mathrm{HC}^{18} \mathrm{O}^{+}$ & 1 \\
$\mathrm{SO}_{2}$ & 32 & $\mathrm{HC}_{3} \mathrm{~N}$ & 3 \\
${ }^{34} \mathrm{SO}{ }_{2}$ & 19 & $\mathrm{CH}_{3} \mathrm{CCH}$ & 11 \\
$\mathrm{C}_{2} \mathrm{H}$ & 2 & $\mathrm{CH}_{3} \mathrm{CN}$ & 8 \\
$\mathrm{CS}^{34} \mathrm{C}$ & 1 & $\mathrm{CH}_{3} \mathrm{OH}$ & 18 \\
$\mathrm{C}^{34} \mathrm{CH}$ & $\mathrm{H}_{2} \mathrm{CO}$ & 1 \\
$\mathrm{C}^{33} \mathrm{~S}$ & 1 & $\mathrm{H}_{2} \mathrm{CS}$ & 6 \\
$\mathrm{OCS}$ & 2 & $\mathrm{U}$ & 6 \\
$\mathrm{CN}$ & 8 & & \\
\hline
\end{tabular}

(Poynter \& Pickett 1985). Other lists used include Lovas (1992), the methanol lists of Anderson et al. (1993) and the observational lists of lines seen by Jewell et al. (1989) toward Orion-A, Schilke et al. (1997b) toward Orion-KL and Macdonald et al. (1996) toward G34.26+0.15.

\section{Results}

\subsection{Identified lines and their profiles}

142 lines originating from a total of 19 species were detected and are shown in Table 5. 6 further lines could not be identified and are indicated as such by $U$ in Table 5 . Many isotopomers were detected, particularly the ${ }^{34} \mathrm{SO}_{2}$ isotopomer. A list of the identified species (including isotopomers) and the total number of lines from each is given in Table 1. Approximately $50 \%$ of the identified lines originate from sulphur-bearing species. Many of these lines (e.g. $\mathrm{CS}, \mathrm{SO}, \mathrm{SO}_{2}$ and to some extent $\mathrm{C}^{34} \mathrm{~S}$ and ${ }^{34} \mathrm{SO}$ ) exhibit broad line wings suggesting that their emission originates from regions of wide velocity dispersion, perhaps from the molecular outflow. Other non sulphurbearing species known as typical outflow tracers (CO, $\left.\mathrm{HCO}^{+}, \mathrm{CH}_{3} \mathrm{OH}\right)$ also display a wide range of velocities. Isotopomers such as ${ }^{13} \mathrm{CO}, \mathrm{H}^{13} \mathrm{CO}^{+}$and $\mathrm{C}^{34} \mathrm{~S}$ have broad line wings, which indicates that the outflowing gas has a significant optical depth in these molecules. The density tracer HCN also appears to have broad line wings, although this is complicated by the presence of two image band $\mathrm{SO}_{2}$ lines blended with the $\mathrm{HCN} 4-3$ line. $\mathrm{SiO}$ exhibits extremely broad emission (across $\sim 50 \mathrm{~km} \mathrm{~s}^{-1}$ ), however it is again unfortunately blended with a vibrational $\mathrm{SO}_{2}$ line in the image band.

In contrast to the broad lines thought to have an origin within the outflow, several species with narrow line profiles (e.g. $\mathrm{HC}_{3} \mathrm{~N}, \mathrm{CH}_{3} \mathrm{CN}, \mathrm{CH}_{3} \mathrm{CCH}, \mathrm{NO}$ ) trace a relatively quiescent region of gas, probably the molecular envelope surrounding the UC HII region (Gomez et al. 1991).

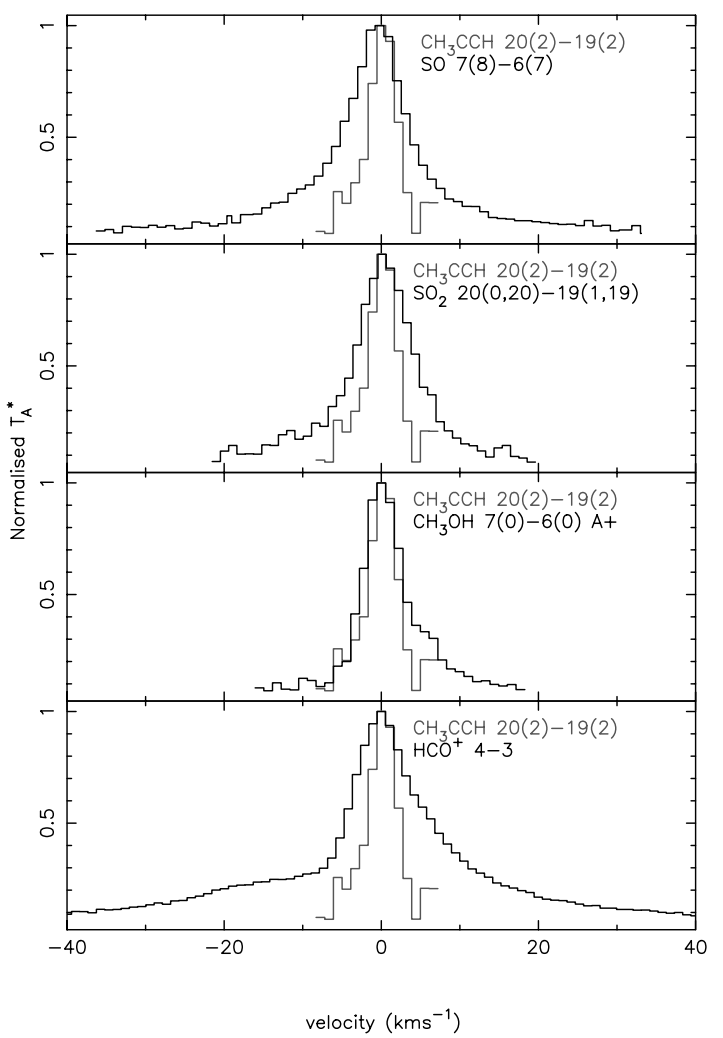

Fig. 2. Spectra of broad lines from species known to probe outflows are compared to the $\mathrm{CH}_{3} \mathrm{CCH} 20(2)-19(2)$ line. Broad red and blue-shifted wings are clearly visible in the $\mathrm{SO}, \mathrm{SO}_{2}$ and $\mathrm{HCO}^{+}$lines, whereas the $\mathrm{CH}_{3} \mathrm{OH} 7(0)-6(0) \mathrm{A}+$ line only clearly exhibits a red-shifted wing

Figure 2 shows a selection of high-velocity lines compared with the $\mathrm{CH}_{3} \mathrm{CCH} 20(2)-19(2)$ line as representative of the low velocity dispersion lines. The temperature scale is normalised to highlight the differences between them. The differences between the narrow $\mathrm{CH}_{3} \mathrm{CCH}$ line which probes the gas of the molecular envelope and the broad lines of the outflow tracers $\mathrm{SO}, \mathrm{SO}_{2}$ and $\mathrm{HCO}^{+}$are obvious. The $\mathrm{CH}_{3} \mathrm{OH}$ line also has a distinct red wing.

In contrast to other high-mass YSO sources such as G34.26+0.15 and Orion-KL, there is no observational evidence of the presence of heavy organic molecules such as ethyl cyanide $\left(\mathrm{CH}_{3} \mathrm{CH}_{2} \mathrm{CN}\right)$, methyl formate $\left(\mathrm{HCOOCH}_{3}\right)$ or dimethyl ether $\left(\mathrm{CH}_{3} \mathrm{OCH}_{3}\right)$. These molecules have large numbers of emission lines detected towards the other sources and are evidence of a complex hot core chemistry, which may be absent in the molecular gas associated with G5.89-0.39.

\subsection{Integrated intensities}

We have also compared the total integrated intensities from each molecule, in a similar manner to that of the Orion-KL survey (Schilke et al. 1997b). It is interesting to compare the results from G5.89 with those of OrionKL. In Orion-KL the most dominant molecule in terms of 
Table 2. Integrated intensity for each species. The integrated intensities have been evaluated using the $T_{\mathrm{A}}^{*}$ scale. Where it has not been possible to place a firm value on the total integrated intensity due to blended lines an upper limit is indicated

\begin{tabular}{|l|r|}
\hline Molecule & $\begin{array}{r}\text { Total integrated } \\
\text { intensity (K MHz) }\end{array}$ \\
\hline $\mathrm{CO}$ & $<2049.8$ \\
$\mathrm{SO}_{2}$ & $<829.2$ \\
$\mathrm{SO}^{+}$ & 514.9 \\
$\mathrm{HCO}^{+}$ & 462.5 \\
$\mathrm{HCN}$ & $<340.6$ \\
$\mathrm{CH}_{3} \mathrm{OH}$ & $<300.5$ \\
$\mathrm{CS}$ & 251.6 \\
$\mathrm{CN}$ & 189.7 \\
$\mathrm{H}_{2} \mathrm{CO}$ & 120.6 \\
$\mathrm{C}_{2} \mathrm{H}$ & 93.9 \\
$\mathrm{CH}$ & $\mathrm{CCH}$ \\
$\mathrm{H}_{2} \mathrm{CS}$ & 81.0 \\
$\mathrm{SiO}$ & 64.8 \\
$\mathrm{CH}_{3} \mathrm{CN}$ & $<40.0$ \\
$\mathrm{HC}$ & 35.4 \\
$\mathrm{NO}$ & 29.1 \\
$\mathrm{HNC}$ & 23.2 \\
$\mathrm{OCS}$ & 13.0 \\
$\mathrm{HCS}$ & 10.8 \\
$\mathrm{HNCO}$ & 7.9 \\
\hline
\end{tabular}

integrated intensity is $\mathrm{SO}_{2}$ which has a total integrated intensity more than twice that of CO. In G5.89-0.39 the most dominant molecule is $\mathrm{CO}$ with twice the integrated intensity of $\mathrm{SO}_{2}$. This is due to beam dilution, since G5.89-0.39 is approximately 4 times more distant than Orion KL. The same effect can be seen in other species such as $\mathrm{CH}_{3} \mathrm{CCH}$ and $\mathrm{CH}_{3} \mathrm{CN}$; in Orion-KL the former is much less important for cooling the gas than the latter. However in $\mathrm{G} 5.89 \mathrm{CH}_{3} \mathrm{CCH}$ has twice the integrated intensity of $\mathrm{CH}_{3} \mathrm{CN}$. This is probably due to the property of $\mathrm{CH}_{3} \mathrm{CCH}$ of tracing more extended gas (by virtue of its lower dipole moment), making $\mathrm{CH}_{3} \mathrm{CCH}$ less affected by beam dilution. Care must be taken in interpretations such as this though, as genuine chemical differences may affect the relative abundances of particular species between the two clouds and hence their integrated intensities.

\subsection{Rotation diagrams and lower limits to column density}

The rotation diagram approach assumes optically thin gas in LTE, for which the (beam-averaged) column density $(N)$ can be written as:

$N=\frac{3 k}{8 \pi^{3}} \frac{\int T_{\mathrm{R}} \mathrm{d} v}{\nu S \mu^{2} g_{\mathrm{I}} g_{\mathrm{K}}} Q\left(T_{\text {rot }}\right) \exp \left(\frac{E_{\mathrm{u}}}{k T_{\text {rot }}}\right)$

where $\int T_{\mathrm{R}} \mathrm{d} v$ is the integrated intensity of the line, $\nu$ is the line frequency, $S$ is the line strength, $\mu$ is the permanent electric dipole moment, $g_{\mathrm{I}}$ and $g_{\mathrm{K}}$ are the reduced nuclear spin degeneracy and the K-level degeneracy of the molecule respectively. $E_{\mathrm{u}}$ is the energy of the upper level of the line and $T_{\text {rot }}$ is the rotational temperature of the molecules comprising the gas and $Q\left(T_{\text {rot }}\right)$ is the corresponding partition function. Values for $Q\left(T_{\text {rot }}\right)$ were obtained by interpolating the values given in the JPL molecular line database to the appropriate temperature. Equation (1) was rearranged to an equation for a straight line and $T_{\text {rot }}$ and $N$ for each species were determined by a least-squares fit. A rotation diagram for ${ }^{33} \mathrm{SO}$ was not constructed owing to the lack of well-determined molecular parameters, such as the partition function. Lower limits to the column densities $\left(N_{\min }\right)$ of the remaining species were evaluated using the minimum point of Eq. (1), which occurs at $T_{\text {rot }}=E_{\mathrm{u}} / k$ for linear molecules and $T_{\text {rot }}=\frac{2}{3} E_{\mathrm{u}} / k$ for symmetric and asymmetric top molecules. Both methods are described more fully in Hatchell et al. (1998a).

The results of the rotation diagram and lower limit analyses are given in Tables 3 and 4 . Abundances have been calculated for the rotation diagram species by assuming a spherical cloud with a radius of $0.2 \mathrm{pc}$ and a number density $n\left(\mathrm{H}_{2}\right)=10^{4} \mathrm{~cm}^{-3}$ (taken from Gomez et al. 1991). The abundance of ${ }^{34} \mathrm{SO}_{2}$ indicates that the $\mathrm{SO}_{2}$ abundance may be underestimated due to optical depth effects and should be closer to $310^{6}$. The rotation diagrams are shown in Fig. 3. Certain lines have been excluded from the analysis; self-absorbed and blended lines, and those lines that could not be unambiguously identified with a single species. The data from $\mathrm{SO},{ }^{34} \mathrm{SO}$ and $\mathrm{H}_{2} \mathrm{CS}$ did not give a satisfactory fit to a straight line and lower limits to column density have been evaluated for these molecules.

The rotation diagrams indicate that the molecular gas associated with G5.89 has a temperature of roughly $60-70 \mathrm{~K}$ and a column density of $\sim 10^{15} \mathrm{~cm}^{-2} . \mathrm{SO}_{2}$ appears to probe somewhat hotter gas with temperature in excess of $100 \mathrm{~K}$. The temperature for the less optically thick ${ }^{34} \mathrm{SO}_{2}$ is higher than that of $\mathrm{SO}_{2}$ which is consistent with (although not conclusive evidence for) the temperature of the molecular gas increasing towards the centre.

\section{Discussion}

The results of the survey show that the molecular gas associated with G5.89 does not have such a complex chemistry as other massive YSOs (G34.26+0.15 and Orion-KL). Roughly an eighth of the number of lines seen toward Orion-KL (Schilke et al. 1997b) and a half of the number of lines detected toward G34.26+0.15 (Macdonald et al. 1996) were seen in this survey. 19 species were detected, mostly sulphur-bearing, as opposed to the 35 species seen in the G34.26 and Orion-KL surveys. No lines of heavy organic species (e.g. $\mathrm{CH}_{3} \mathrm{OCH}_{3}, \mathrm{HCOOCH}_{3}$, $\mathrm{CH}_{3} \mathrm{CH}_{2} \mathrm{CN}$ ) were detected. We note that $\lambda=1.3 \mathrm{~mm}$ lines of $\mathrm{HCOOCH}_{3}$ and $\mathrm{CH}_{2} \mathrm{CHCN}$ were detected toward G5.89 by Acord et al. (1997), the prevalent lines of these species seen in the $330-360 \mathrm{GHz}$ range toward Orion-KL and G34.26+0.15 were not detected in this survey. This may be due to the sensitivity limit of this survey, the lines of these species detected in G34.26 are often weak with 

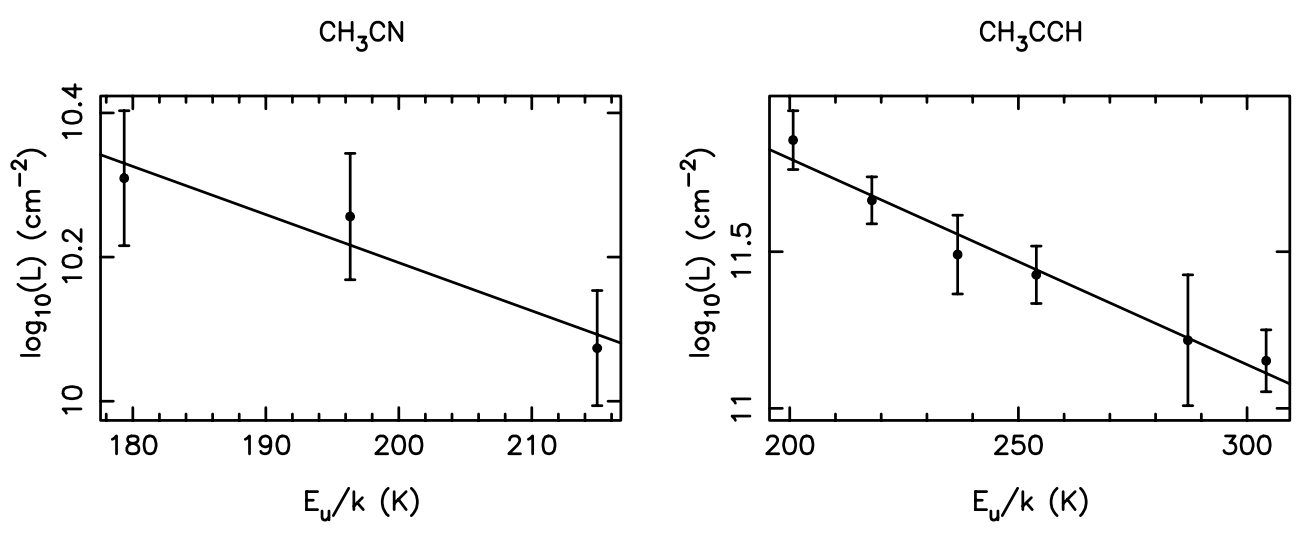

$\mathrm{CH}_{3} \mathrm{OH}$ A-type
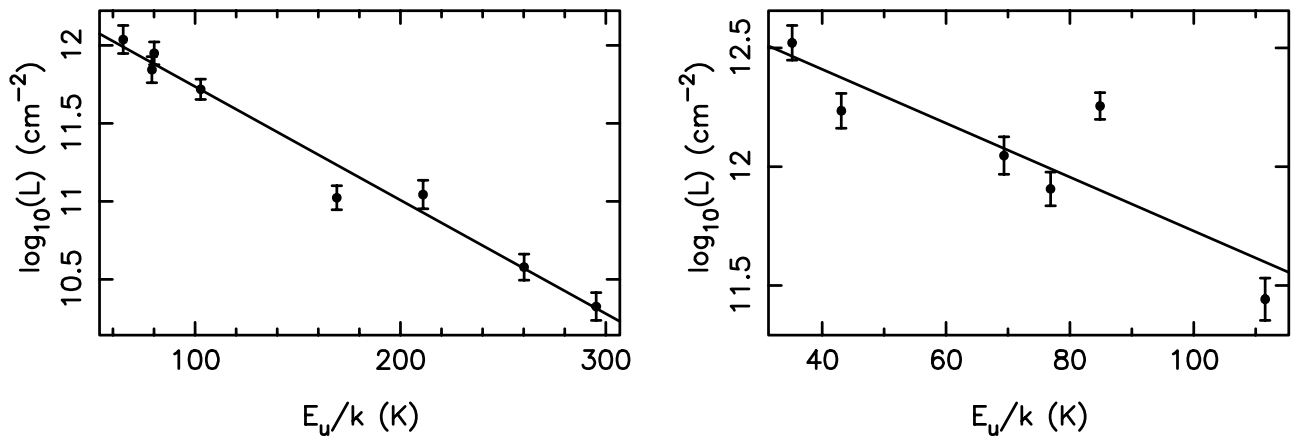

$\mathrm{SO}_{2}$
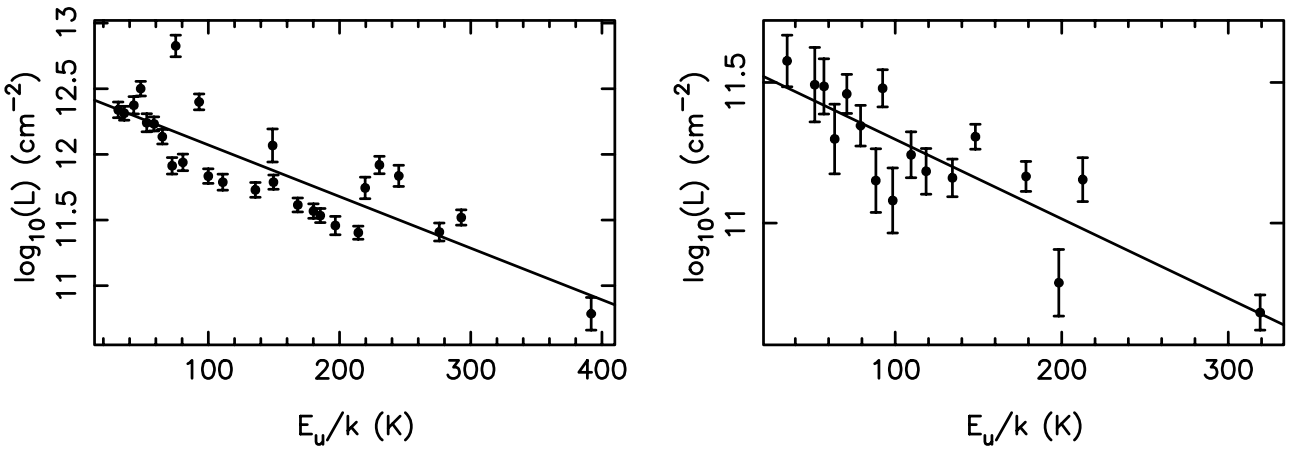

$\mathrm{HC}_{3} \mathrm{~N}$

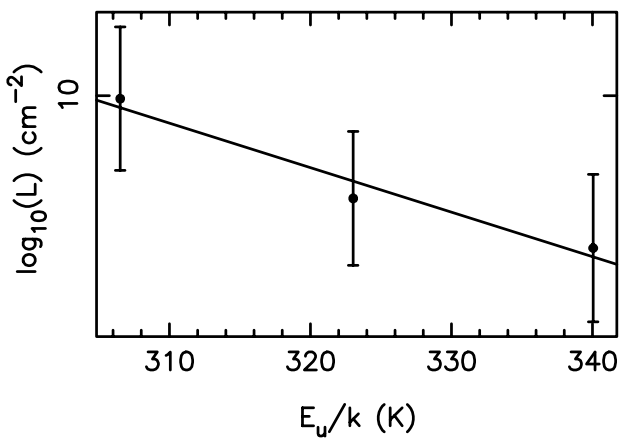

Fig. 3. Rotation diagrams for species with sufficient detected lines 
Table 3. Rotation temperatures $\left(T_{\text {rot }}\right)$, partition functions $\left(Q\left(T_{\text {rot }}\right)\right)$, column densities $(N)$ and abundances $(X)$ relative to $\mathrm{H}_{2}$. Abundances were calculated assuming a spherical envelope with the radius and number density $n\left(\mathrm{H}_{2}\right)$ given in Gomez et al. (1991)

\begin{tabular}{|l|c|c|c|c|}
\hline Species & $T_{\text {rot }}(\mathrm{K})$ & $Q\left(T_{\text {rot }}\right)$ & $N\left(\mathrm{~cm}^{-2}\right)$ & $X\left(\mathrm{H}_{2}\right)$ \\
\hline $\mathrm{CH}_{3} \mathrm{CN}$ & $65 \pm 19$ & 3151 & $1.1 \pm 0.610^{15}$ & $3.610^{-7}$ \\
$\mathrm{CH}_{3} \mathrm{CCH}$ & $66 \pm 6$ & 575 & $7.4 \pm 1.410^{15}$ & $2.410^{-7}$ \\
$\mathrm{CH}_{3} \mathrm{OH} \mathrm{A}$ & $60 \pm 4$ & 590 & $1.7 \pm 0.210^{15}$ & $5.610^{-7}$ \\
$\mathrm{CH}_{3} \mathrm{OH} \mathrm{E}$ & $38 \pm 11$ & 294 & $2.1 \pm 1.110^{15}$ & $6.810^{-7}$ \\
$\mathrm{SO}_{2}$ & $111 \pm 14$ & 1378 & $4.0 \pm 0.910^{15}$ & $1.310^{-6}$ \\
${ }^{34} \mathrm{SO}_{2}$ & $154 \pm 25$ & 2212 & $8.4 \pm 2.110^{14}$ & $2.810^{-7}$ \\
$\mathrm{HC}_{3} \mathrm{~N}$ & $72 \pm 15$ & 996 & $6.6 \pm 2.110^{14}$ & $2.210^{-7}$ \\
\hline
\end{tabular}

Table 4. Lower limits to column density. The partition function $Q$ evaluated at $T_{\mathrm{ex}}$ is also given, where $T_{\mathrm{ex}}=E_{\mathrm{u}} / k$ for linear molecules and $\frac{2}{3} E_{\mathrm{u}} / k$ for symmetric and asymmetric tops. Where two lines were used to evaluate the lower limit the partition functions of both lines are given

\begin{tabular}{|l|c|r|l|c|r|}
\hline Species & $Q\left(T_{\text {ex }}\right)$ & $N_{\min }\left(\mathrm{cm}^{-2}\right)$ & Species & $Q\left(T_{\text {ex }}\right)$ & $N_{\min }\left(\mathrm{cm}^{-2}\right)$ \\
\hline${ }^{13} \mathrm{CO}$ & 12 & $1.110^{17}$ & $\mathrm{HCN}$ & 20 & $6.010^{14}$ \\
$\mathrm{CS}$ & 56 & $4.610^{14}$ & $\mathrm{HC}^{15} \mathrm{~N}$ & 20 & $9.410^{12}$ \\
$\mathrm{C}^{34} \mathrm{~S}$ & 56 & $1.1810^{14}$ & $\mathrm{HN}^{13} \mathrm{C}$ & 20 & $8.010^{12}$ \\
$\mathrm{HCO}^{+}$ & 20 & $1.6310^{14}$ & $\mathrm{C}_{2} \mathrm{H}$ & 40 & $2.110^{15}$ \\
$\mathrm{H}^{13} \mathrm{CO}^{+}$ & 20 & $1.9410^{13}$ & $\mathrm{OCS}$ & $812 / 870$ & $3.4710^{14}$ \\
$\mathrm{HC}^{18} \mathrm{O}^{+}$ & 20 & $2.110^{12}$ & $\mathrm{SO}$ & $413 / 235$ & $4.110^{15}$ \\
$\mathrm{H}_{2} \mathrm{CS}$ & $1118 / 687$ & $1.510^{15}$ & ${ }^{34} \mathrm{SO}$ & $231 / 224$ & $3.010^{14}$ \\
\hline
\end{tabular}

peak $T_{\mathrm{A}}^{*} \sim 0.5 \mathrm{~K}$ (compared to the rms noise of this survey of $0.1 \mathrm{~K}$ at $1.25 \mathrm{MHz}$ resolution). However there are several lines in the frequency range of the survey that exhibited strong emission from G34.26 (peak $T_{\mathrm{A}}^{*} \geq 0.8 \mathrm{~K}$ ) and are noticeably absent in this survey. More sensitive observations targeted toward these species may be necessary to confirm that their absence is due to chemical processes.

The temperature of the gas associated with G5.89 is $60-80 \mathrm{~K}$, as shown by the rotation diagrams of $\mathrm{CH}_{3} \mathrm{CN}$, $\mathrm{CH}_{3} \mathrm{CCH}$ and $\mathrm{HC}_{3} \mathrm{~N}$. This is reasonably consistent with the temperature of the molecular envelope (90 K) derived from $\mathrm{NH}_{3}$ by Gomez et al. (1991). $\mathrm{SO}_{2}$ and ${ }^{34} \mathrm{SO}_{2}$ appear to probe hotter gas with temperatures of $110-150 \mathrm{~K}$. ${ }^{34} \mathrm{SO}_{2}$ has a higher rotation temperature which is consistent with a temperature gradient increasing toward the centre of the gas. The column densities of most species are in the range $10^{14}-10^{15} \mathrm{~cm}^{-2}$. The temperature and density of many of the species in this survey are much less than the corresponding species in the surveys of G34.26 (Macdonald et al. 1996) and Orion-KL (Schilke et al. 1997b). The most striking difference is for $\mathrm{CH}_{3} \mathrm{OH}$, which in G34.26 and Orion-KL has a rotation temperature of 340 and $190 \mathrm{~K}$ respectively but a rotation temperature of only $65 \mathrm{~K}$ in G5.89.

Inspection of the line profiles indicates that the chemistry of the molecular gas proceeds in two very different physical regimes: that in the molecular envelope surrounding the UC HII and that in the shocked gas of the molecular outflow. In the former the species tracing the envelope are those such as $\mathrm{CH}_{3} \mathrm{CN}, \mathrm{CH}_{3} \mathrm{CCH}$ and $\mathrm{HC}_{3} \mathrm{~N}$; in the latter sulphur- and silicon-bearing species with broad line profiles perhaps trace the chemistry of the outflow. Here, we will examine the broad details of the survey in order to set out the most useful approaches to investigate the chemistry of G5.89-0.39. The approaches outlined here will be elaborated upon more quantatively in Paper II.

The chemistry of the envelope could be explained in terms of hot core chemical models (e.g. Millar et al. 1997 and references therein). Hot core models follow the evolution of the gas-phase chemistry of evaporated grain-mantle ices, where the evaporation is assumed to be caused by the "switch-on" of a nearby high-mass star. The hot core is usually extremely compact and dense with $n_{\mathrm{H}_{2}}$ around $10^{6}-10^{7} \mathrm{~cm}^{-3}$. Temperatures can range from $100-250 \mathrm{~K}$ and the chemistry is characterised by anomalously high abundances of saturated species (e.g. $\mathrm{H}_{2} \mathrm{~S}$ and $\mathrm{NH}_{3}$ ) and large molecules such as $\mathrm{C}_{2} \mathrm{H}_{5} \mathrm{OH}$ and $\mathrm{CH}_{3} \mathrm{OCH}_{3}$. The nature of the envelope surrounding G5.89 has some parallels with hot core chemistry; there are high column densities of warm $(\sim 90 \mathrm{~K})$ ammonia in close association with the young O-star (or stars) powering the UC HII region. There are however some differences between the molecular envelope and the standard picture of hot cores. G5.89 has the one of the lowest abundances of ammonia as seen in the UC HII region sample of Cesaroni et al. (1992), by roughly a factor of 10 . The $\mathrm{H}_{2}$ density lies between a few $10^{4}$ and $10^{6} \mathrm{~cm}^{-3}$ (Gomez et al. 1991 and Cesaroni et al. 1992). The molecular gas does not exhibit any detectable emission from large molecules, unlike the more line-rich 
sources from the UC HII region survey of Hatchell et al. (1998a).

Hot core models may be able to explain these differences from the standard picture. We have examined the model of Millar et al. (1997) which is tailored for G34.26+0.15. The model takes account of the cloud structure as derived from the radiative transfer modelling of $\mathrm{HCO}^{+}$(Heaton et al. 1993) and CO (Little et al. 1994). The cloud in which G34.26 is embedded has three hierarchical components; a cold rarefied halo approximately $3.5 \mathrm{pc}$ in radius, a compact core of radius $0.1 \mathrm{pc}$ and an inner dense ultracompact core of radius $0.01 \mathrm{pc}$. The compact core quite closely matches the conditions in the envelope of G5.89 (the model temperature and $\mathrm{H}_{2}$ density are $\sim 80 \mathrm{~K}$ and $10^{6} \mathrm{~cm}^{-3}$ respectively). The compact core model shows that the abundances of the heavy organic molecules decrease as the core ages, falling off sharply beyond roughly $10^{5}$ years. The compact core model is able to reproduce the abundances observed in the survey to within a factor of 10 , with the exception of $\mathrm{CH}_{3} \mathrm{CCH}$ which is under-produced in the model by at least three orders of magnitude. The observations are consistent with a chemical evolution time of $\geq 10^{5}$ years, although such a direct comparison of the model which is tailored for G34.26 and the observed abundances which are dependent on the geometry of G5.89 must be viewed with caution.

This must be reconciled with the apparent youth of the UC HII region. Recent high resolution astrometric observations have revealed that the HII region is expanding at a rate consistent with a dynamical age of $\sim 600$ years (Acord et al. 1998). However the onset of the UC HII region may have been delayed by high gas and dust densities in the early phases of star formation and the gas accreting onto the massive protostar may have undergone heating prior to stellar "switch-on", perhaps from dynamical sources such as accretion shocks or outflow shocks. Another problem which addressed is that in hot core models the abundance of sulphur-bearing species such as $\mathrm{H}_{2} \mathrm{~S}$ and $\mathrm{SO}$ decreases after roughly $10^{3}$ years for $\mathrm{H}_{2} \mathrm{~S}$ and $10^{4}$ years for $\mathrm{SO}$. The abundance of $\mathrm{SO}_{2}$ stays enhanced until roughly $10^{6}$ years. The hot core model is capable of reproducing the observed $\mathrm{SO}_{2}$ abundances of $10^{-6}-10^{-7}$ at a temperature of $100 \mathrm{~K}$ (Hatchell et al. 1998b), however the broad line wings of $\mathrm{SO}$ and $\mathrm{SO}_{2}$ lines show that there must be a connection between the outflowing gas and the sulphur species.

Shock-driven chemical models predict the enhancement of sulphur-bearing species (e.g. Pineau-des-Fôrets et al. 1993; Draine et al. 1983), particularly $\mathrm{H}_{2} \mathrm{~S}$ and $\mathrm{SO}_{2}$. A shock passing through molecular gas will heat and compress the gas, permitting reactions with activation energy barriers to proceed. The reactions $\mathrm{O}+\mathrm{H}_{2} \rightarrow \mathrm{OH} \rightarrow \mathrm{H}_{2} \mathrm{O}$ and $\mathrm{S}+\mathrm{H}_{2} \rightarrow \mathrm{SH} \rightarrow \mathrm{H}_{2} \mathrm{~S}$ rapidly process the available oxygen and sulphur into $\mathrm{H}_{2} \mathrm{O}$ and $\mathrm{H}_{2} \mathrm{~S}$. Reactions with $\mathrm{OH}$ and $\mathrm{O}_{2}$ convert the $\mathrm{H}_{2} \mathrm{~S}$ into $\mathrm{SO}$ and $\mathrm{SO}_{2}$, which peak in abundance further behind the shock than $\mathrm{H}_{2} \mathrm{~S}$. The model of Pineau-des-Fôrets et al. (1993) predicts an $\mathrm{SO}_{2}$ abundance of $\sim 10^{-6}$ which is consistent with that observed.

The shocks also strip the ice mantles from dust grains, by thermal processes, sputtering (Schilke et al. 1997a) and grain-grain collisions (Caselli et al. 1997). Depending on the shock speed one or more of these processes may dominate overall and at high enough shock speeds grains may be completely disrupted (e.g. J-shocks with speeds of $>40 \mathrm{~km} \mathrm{~s}^{-1}$, Seab \& Schull 1983). This disruption of grain cores or mantles injects depleted species into the gas phase, altering the chemical composition significantly. Chemical models involving grain disruption have been constructed for $\mathrm{SiO}$ and $\mathrm{H}_{2} \mathrm{O}$ (e.g. Schilke et al. 1997a; Bergin et al. 1998) but not explicitly for sulphur-bearing species. Significant quantities of $\mathrm{H}_{2} \mathrm{~S}$ may be injected into the gas phase directly from grain mantles, rather than by hydrogenation of elemental sulphur.

It is also difficult to distinguish the route towards the production of sulphur-bearing species. Hot core chemistry alone can reproduce the observed abundances of sulphurbearing species (Charnley 1997; Hatchell et al. 1998b). The chemical pathways are similar but for the formation of $\mathrm{H}_{2} \mathrm{~S}$, which instead of being formed by hydrogenation of elemental sulphur is directly evaporated from grain ice mantles. However the survey shows that many sulphurbearing species are likely to be located within the outflowing gas, by virtue of their broad line profiles. We intend to explore the mechanisms behind the sulphur species production further by detailed physical analysis and modelling of hot core and shock-driven chemistry in the companion paper (Paper II).

\section{Summary and conclusions}

We have performed a $330-360 \mathrm{GHz}$ molecular line survey of the molecular gas associated with the UC HII region G5.89-0.39. The lines detected in the survey can be split into two types; those with narrow line profiles which probe the dense molecular envelope surrounding the UC HII region and those with broad line wings which probably arise from the massive outflow known to be associated with G5.89-0.39. The species which exhibit high-velocity emission are consistent with those seen toward outflows from low-mass YSOs, indicating that similar processes are responsible for the chemical evolution of outflowing gas. The rotation temperature of the species detected in the survey is $60-80 \mathrm{~K}$ and the column densities of most species are in the range $10^{14}-10^{15} \mathrm{~cm}^{-2}$.

No heavy organic species (e.g. $\mathrm{CH}_{3} \mathrm{OCH}_{3}, \mathrm{CH}_{2} \mathrm{CHCN}$ ) were detected. The spectrum is dominated by lines of sulphur-bearing species; over $50 \%$ of the identified lines originate from sulphur-bearing species. The dominant molecule in terms of integrated intensity is $\mathrm{CO}$, which has twice the integrated intensity of $\mathrm{SO}_{2}$. This is the opposite of the situation in Orion-KL (Schilke et al. 1997b) where $\mathrm{SO}_{2}$ has twice the integrated intensity of $\mathrm{CO}$. Beam dilution is the most likely cause. 
The chemistry of G5.89 has features that are similar to hot core and shock-driven models. The broad features of the envelope chemistry are similar to those of hot cores with the caveats that the density and temperature are lower than in other hot core sources and that there is no evidence of the heavy organic molecules seen in the hot core surveys of Macdonald et al. (1996), Schilke et al. (1997b) and Hatchell et al. (1998a). It is possible that the envelope of G5.89 is evolved much further than the dynamical ages of both the UC HII region and outflow suggest. We intend to subject the survey data to detailed physical and chemical analysis in a following paper, in order to derive the physical parameters of the molecular gas and to model the chemistry of the envelope and outflow to determine whether the chemical evolution can be better described by hot core or shock-driven models.

Interferometric observations would also be extremely useful in determining the locations of the sulphur-bearing species and to confirm whether shock-driven chemistry or hot core chemistry is the prime cause. Acord et al. (1997) remark upon the similarity of the line profiles of $\mathrm{SiO}, \mathrm{NH}_{3}$ and $\mathrm{CO}$ at high velocities, perhaps suggesting that these three species are coexistent in the outflow. Interferometric observation of these species would confirm this and allow the refinement of models of the chemistry and physics of outflow shocks.

Acknowledgements. MAT would like to thank PPARC for their support via a research studentship and the JCMT staff for all their assistance during the observations.

\section{References}

Acord J.M., Walmsley C.M., Churchwell E., 1997, ApJ 475, 693

Acord J.M., Churchwell E., Wood D.O.S., 1998, ApJ 495, 107

Anderson T., Herbst E., Delucia F.C., 1993, J. Mol. Spectrosc. 159,410

Bachiller R., 1996, ARA\&A 34, 111

Bachiller R., Perez-Gutierrez M., 1997, ApJ 487, L93

Bergin E.A., Melnick G.J., Neufeld D.A., 1998, ApJ 499, 777

Blake G.A., Sandell G., van Dishoeck E.F., Groesbeck T.D., Mundy L.G., Aspin C., 1995, ApJ 441, 689

Cabrit S., Bertout C., 1992, A\&A 261, 274
Caselli P., Hartquist T.W., Havnes O., 1997, A\&A 322, 296

Cesaroni R., Walmsley C.M., Churchwell E., A\&A 256, 618

Charnley S.B., 1997, ApJ 481, 396

Churchwell E., 1997, ApJ 479, L59

De Young D.S., 1986, ApJ 263, L73

Draine B.T., Roberge W.G., Dalgarno A., 1983, ApJ 264, 485

Fukui Y., Iwata T., Mizuno A., Bally J., Lane A.P., 1993, in Protostars \& Planets III, Levy E.H. \& Lunine J.I. (eds.). Tucson: Univ. Ariz. Press, pp. 603-39

Gomez Y., Rodriguez L.F., Garay G., Moran J.M., 1991, ApJ 377,519

Harvey P.M., Forveille T., 1988, A\&A 197, L19

Harvey P.M., Lester D.F., Colomé C., et al., 1994, ApJ 433, 187

Hatchell J., Thompson M.A., Millar T.J., Macdonald G.H., 1998a, A\&AS (in press)

Hatchell J., Thompson M.A., Millar T.J., Macdonald G.H., 1998b, A\&A 338, 713

Heaton B.D., Little L.T., Yamashita T., et al., 1993, A\&A 278, 238

Jewell P.R., Hollis J.M., Lovas F.J., Snyder L.E., 1989, ApJS 70,833

Kutner M.L., Ulich B.L., 1981, ApJ 250, 341

Little L.T., Gibb A.G., Heaton B.D., Ellison B.N., Claude S.M.X., 1994, MNRAS 271, 649

Macdonald G.H., Gibb A.G., Habing R.J., Millar T.J., 1996, A\&AS 119, 333 (Paper I)

Millar T.J., Macdonald G.H., Gibb A.G., 1997, A\&A 325, 1163

Pelletier G., Pudritz R.E., 1992, ApJ 394, 117

Pineau-des-Fôrets G., Roueff E., Schilke P., Flower D.R., 1993, MNRAS 262, 915

Plume R., Jaffe D.T., Evans N.J. II, Martin-Pintado J., Gomez-Gonzalez J., 1997, ApJ 476, 730

Poynter R.L., Pickett H.M., 1985, Appl. Opt. 24, 2335

Schilke P., Walmsley C.M., Pineau-de-Fôrets G., Flower D.R., 1997a, A\&A 321, 293

Schilke P., Groesbeck T.D., Blake G.A., Phillips T.G., 1997b, ApJS 108, 301

Seab C.G., Shull J.M., 1983, ApJ 275, 652

Shepherd D.S., Churchwell E., 1996a, ApJ 457, 267

Shepherd D.S., Churchwell E., 1996b, ApJ 472, 225

Shepherd D.S., Watson A.M., Sargent A.I., Churchwell E., 1998, ApJ (in press)

Shu F.H., Najita J., Ostriker E.C., Shang H., 1995, ApJ 455, L155

Wood D.O.S., Churchwell E., 1989, ApJS 69, 831 
Table 5. The measured line parameters of observed frequency $(\nu(\mathrm{obs}))$, peak temperature $\left(T_{\mathrm{A}}^{*}\right)$ and line width $\left(\Delta \nu_{1 / 2}\right)$ for each detected line are listed here. Multiple detections of the same line have been included. Lines that are blended are indicated in the Notes column by blended if they are blended with a different species or $h / f i n e s$ if they are a mixture of two or more hyperfine components. Self-absorbed lines are also listed. Blended lines that can have one or both components extracted are indicated by sl-blend

\begin{tabular}{|c|c|c|c|c|c|c|c|}
\hline $\begin{array}{l}\nu(\mathrm{obs}) \\
(\mathrm{GHz}) \\
\end{array}$ & $\begin{array}{l}T_{\mathrm{A}}^{*} \\
(\mathrm{~K}) \\
\end{array}$ & $\begin{array}{l}\Delta \nu_{1 / 2} \\
(\mathrm{MHz}) \\
\end{array}$ & Species & Transition & $\begin{array}{l}\nu(\text { rest }) \\
(\mathrm{GHz}) \\
\end{array}$ & $\begin{array}{c}E_{\mathrm{u}} / k \\
(\mathrm{~K}) \\
\end{array}$ & Notes \\
\hline 330.588 & 19.11 & 8.7 & ${ }^{13} \mathrm{CO}$ & $3-2$ & 330.588 & 31.7 & \\
\hline 331.014 & 0.68 & 6.8 & $\mathrm{CH}_{3} \mathrm{CN}$ & $18(3)-17(3)$ & 331.0143 & 215 & \\
\hline 331.045 & 0.70 & 5.8 & $\mathrm{CH}_{3} \mathrm{CN}$ & $18(2)-17(2)$ & 331.0461 & 180 & \\
\hline 331.066 & 1.01 & & $\mathrm{CH}_{3} \mathrm{CN}$ & $18(1)-17(1)$ & 331.0652 & 158 & blend \\
\hline 331.072 & 0.87 & & $\mathrm{CH}_{3} \mathrm{CN}$ & $18(0)-17(0)$ & 331.0716 & 151 & blend \\
\hline 331.500 & 0.93 & 5.2 & $\mathrm{CH}_{3} \mathrm{OH}$ & $11(1)-11(0) \mathrm{A}-, \mathrm{A}+$ & 331.5024 & 169 & \\
\hline 331.502 & 0.93 & 8.9 & $\mathrm{CH}_{3} \mathrm{OH}$ & $11(1)-11(0) \mathrm{A}-, \mathrm{A}+$ & 331.5024 & 169 & \\
\hline 331.581 & 0.93 & 2.9 & $\mathrm{SO}_{2}$ & $11(6,6)-12(5,7)$ & 331.5803 & 149 & \\
\hline 331.582 & 0.73 & 7.3 & $\mathrm{SO}_{2}$ & $11(6,6)-12(5,7)$ & 331.5803 & 149 & \\
\hline 332.091 & 2.23 & 6.4 & $\mathrm{SO}_{2}$ & $21(2,20)-21(1,21)$ & 332.0914 & 220 & \\
\hline 332.092 & 1.76 & 6.4 & $\mathrm{SO}_{2}$ & $21(2,20)-21(1,21)$ & 332.0914 & 220 & \\
\hline 332.093 & 1.86 & 8.4 & $\mathrm{SO}_{2}$ & $21(2,20)-21(1,21)$ & 332.0914 & 220 & \\
\hline 332.093 & 1.09 & 7.4 & $\mathrm{SO}_{2}$ & $21(2,20)-21(1,21)$ & 332.0914 & 220 & \\
\hline 332.506 & 2.61 & 8.7 & $\mathrm{SO}_{2}$ & $4(3,1)-3(2,2)$ & 332.5053 & 31.3 & \\
\hline 332.506 & 2.43 & 8.8 & $\mathrm{SO}_{2}$ & $4(3,1)-3(2,2)$ & 332.5053 & 31.3 & \\
\hline 332.571 & 0.47 & 3.4 & $\mathrm{U}$ & & & & \\
\hline 333.901 & 1.87 & 6.2 & ${ }^{34} \mathrm{SO}$ & $7(8)-6(7)$ & 333.901 & 79.9 & \\
\hline 333.901 & 1.96 & 6.2 & ${ }^{34} \mathrm{SO}$ & $7(8)-6(7)$ & 333.901 & 79.9 & \\
\hline 334.673 & 2.10 & 7.7 & $\mathrm{SO}_{2}$ & $8(2,6)-7(1,7)$ & 334.6733 & 43.1 & \\
\hline 334.674 & 2.50 & 7.4 & $\mathrm{SO}_{2}$ & $8(2,6)-7(1,7)$ & 334.6733 & 43.1 & \\
\hline 335.574 & 0.63 & & $\mathrm{U}$ & & & & \\
\hline 335.581 & 1.50 & 7.1 & $\mathrm{CH}_{3} \mathrm{OH}$ & $7(1)-6(1) \mathrm{A}+$ & 335.582 & 79 & \\
\hline 335.582 & 1.72 & 6.8 & $\mathrm{CH}_{3} \mathrm{OH}$ & $7(1)-6(1) \mathrm{A}+$ & 335.582 & 79 & \\
\hline 336.089 & 1.37 & 7.8 & $\mathrm{SO}_{2}$ & $23(3,21)-23(2,22)$ & 336.0892 & 276 & \\
\hline 336.090 & 1.42 & 7.8 & $\mathrm{SO}_{2}$ & $23(3,21)-23(2,22)$ & 336.0892 & 276 & \\
\hline 336.520 & 1.40 & 6.1 & $\mathrm{HC}_{3} \mathrm{~N}$ & $37-36$ & 336.5201 & 307 & \\
\hline 336.520 & 1.35 & 4.9 & $\mathrm{HC}_{3} \mathrm{~N}$ & $37-36$ & 336.5201 & 307 & \\
\hline 336.554 & 0.79 & 6.1 & $\mathrm{SO}$ & $10(11)-10(10)$ & 336.5538 & 143 & \\
\hline 336.554 & 0.94 & 6.1 & $\mathrm{SO}$ & $10(11)-10(10)$ & 336.5538 & 143 & \\
\hline 336.670 & 0.75 & 6.1 & $\mathrm{SO}_{2}$ & $16(7,9)-17(6,12)$ & 336.6696 & 245 & \\
\hline 336.670 & 0.77 & 2.2 & $\mathrm{SO}_{2}$ & $16(7,9)-17(6,12)$ & 336.6696 & 245 & \\
\hline 336.670 & 1.24 & 6.1 & $\mathrm{SO}_{2}$ & $16(7,9)-17(6,12)$ & 336.6696 & 245 & \\
\hline 336.671 & 0.66 & 6.1 & $\mathrm{SO}_{2}$ & $16(7,9)-17(6,12)$ & 336.6696 & 245 & \\
\hline 337.062 & 4.72 & 6.1 & $\mathrm{C}^{17} \mathrm{O}$ & $3-2$ & 337.0611 & 32.4 & blend \\
\hline 337.063 & 6.40 & & $\mathrm{C}^{17} \mathrm{O}$ & $3-2$ & 337.0611 & 32.4 & blend \\
\hline 337.198 & 0.69 & 6.5 & ${ }^{33} \mathrm{SO}$ & $8(7)-7(6)$ & 337.1950 & & \\
\hline 337.198 & 0.66 & 7.4 & ${ }^{33} \mathrm{SO}$ & $8(7)-7(6)$ & 337.1950 & & \\
\hline 337.396 & 4.87 & 9.5 & $\mathrm{C}^{34} \mathrm{~S}$ & $7-6$ & 337.3966 & 64.8 & \\
\hline 337.396 & 4.03 & 6.5 & $\mathrm{C}^{34} \mathrm{~S}$ & $7-6$ & 337.3966 & 64.8 & \\
\hline 337.397 & 3.99 & 6.1 & $\mathrm{C}^{34} \mathrm{~S}$ & $7-6$ & 337.3966 & 64.8 & \\
\hline 337.397 & 4.67 & 6.5 & $\mathrm{C}^{34} \mathrm{~S}$ & $7-6$ & 337.3966 & 64.8 & \\
\hline 337.581 & 2.11 & 72 & ${ }^{34} \mathrm{SO}$ & $8(8)-7(7)$ & 337.5802 & 86.1 & \\
\hline 337.581 & 1.99 & 7.2 & ${ }^{34} \mathrm{SO}$ & $8(8)-7(7)$ & 337.5802 & 86.1 & sl-blend \\
\hline 338.082 & 2.61 & 5.2 & $\mathrm{H}_{2} \mathrm{CS}$ & $10(1,10)-9(1,9)$ & 338.081 & 102 & sl-blend \\
\hline 338.084 & 2.48 & 5.1 & $\mathrm{H}_{2} \mathrm{CS}$ & $10(1,10)-9(1,9)$ & 338.081 & 102 & \\
\hline 338.084 & 2.48 & 5.2 & $\mathrm{H}_{2} \mathrm{CS}$ & $10(1,10)-9(1,9)$ & 338.081 & 102 & sl-blend \\
\hline 338.084 & 2.30 & 5.1 & $\mathrm{H}_{2} \mathrm{CS}$ & $10(1,10)-9(1,9)$ & 338.081 & 102 & \\
\hline 338.125 & 2.79 & 6.5 & $\mathrm{CH}_{3} \mathrm{OH}$ & $7(0)-6(0) \mathrm{E}$ & 338.1245 & 76.9 & \\
\hline 338.125 & 1.74 & 4.9 & $\mathrm{CH}_{3} \mathrm{OH}$ & $7(0)-6(0) \mathrm{E}$ & 338.1245 & 76.9 & \\
\hline 338.306 & 1.50 & 8.4 & $\mathrm{SO}_{2}$ & $18(4,14)-18(3,15)$ & 338.306 & 197 & sl-blend \\
\hline 338.306 & 1.25 & 8.5 & $\mathrm{SO}_{2}$ & $18(4,14)-18(3,15)$ & 338.306 & 197 & sl-blend \\
\hline
\end{tabular}


Table 5. continued

\begin{tabular}{|c|c|c|c|c|c|c|c|}
\hline $\begin{array}{l}\nu(\mathrm{obs}) \\
(\mathrm{GHz}) \\
\end{array}$ & $\begin{array}{l}T_{\mathrm{A}}^{*} \\
(\mathrm{~K}) \\
\end{array}$ & $\begin{array}{r}\Delta \nu_{1 / 2} \\
(\mathrm{MHz}) \\
\end{array}$ & Species & Transition & $\begin{array}{c}\nu \text { (rest) } \\
(\mathrm{GHz}) \\
\end{array}$ & $\begin{array}{c}E_{\mathrm{u}} / k \\
(\mathrm{~K}) \\
\end{array}$ & Notes \\
\hline 338.321 & 0.67 & 7.2 & ${ }^{34} \mathrm{SO}_{2}$ & $13(2,12)-12(1,11)$ & 338.3204 & 92.4 & sl-blend \\
\hline 338.321 & 0.75 & 10 & ${ }^{34} \mathrm{SO}_{2}$ & $13(2,12)-12(1,11)$ & 338.3204 & 92.4 & sl-blend \\
\hline 338.345 & 2.63 & 7.4 & $\mathrm{CH}_{3} \mathrm{OH}$ & $7(-1)-6(-1) \mathrm{E}$ & 338.3446 & 69.4 & \\
\hline 338.345 & 2.74 & 6.1 & $\mathrm{CH}_{3} \mathrm{OH}$ & $7(-1)-6(-1) \mathrm{E}$ & 338.3446 & 69.4 & \\
\hline 338.409 & 3.00 & 6.5 & $\mathrm{CH}_{3} \mathrm{OH}$ & $7(0)-6(0) \mathrm{A}+$ & 338.4087 & 65 & \\
\hline 338.409 & 2.79 & 6 & $\mathrm{CH}_{3} \mathrm{OH}$ & $7(0)-6(0) \mathrm{A}+$ & 338.4087 & 65 & \\
\hline 338.513 & 1.45 & & $\mathrm{CH}_{3} \mathrm{OH}$ & $7(2)-6(2) \mathrm{A}-$ & 338.5129 & 103 & blend \\
\hline 338.513 & 1.28 & 6.4 & $\mathrm{CH}_{3} \mathrm{OH}$ & $7(2)-6(2) \mathrm{A}-$ & 338.5129 & 103 & blend \\
\hline 338.542 & 1.40 & & $\mathrm{CH}_{3} \mathrm{OH}$ & $7(3)-6(3) \mathrm{A}+$ & 338.5408 & 115 & blend \\
\hline 338.543 & 1.27 & 7.5 & $\mathrm{CH}_{3} \mathrm{OH}$ & $7(3)-6(3) \mathrm{A}+$ & 338.5408 & 115 & blend \\
\hline 338.584 & 0.62 & 6.1 & $\mathrm{CH}_{3} \mathrm{OH}$ & $7(3)-6(3) \mathrm{E}$ & 338.5832 & 112 & \\
\hline 338.614 & 2.86 & 10 & $\mathrm{CH}_{3} \mathrm{OH}$ & $7(1)-6(1) \mathrm{E}$ & 338.615 & 84.9 & \\
\hline 338.614 & 3.12 & 10 & $\mathrm{CH}_{3} \mathrm{OH}$ & $7(1)-6(1) \mathrm{E}$ & 338.615 & 84.9 & \\
\hline 338.640 & 0.96 & 7.3 & $\mathrm{CH}_{3} \mathrm{OH}$ & $7(2)-6(2) \mathrm{A}+$ & 338.6399 & 103 & \\
\hline 338.640 & 1.22 & 7.4 & $\mathrm{CH}_{3} \mathrm{OH}$ & $7(2)-6(2) \mathrm{A}+$ & 338.6399 & 103 & \\
\hline 338.722 & 2.30 & 7.5 & $\mathrm{CH}_{3} \mathrm{OH}$ & $7(2)-6(2) \mathrm{E}$ & 338.7216 & 86.1 & blend \\
\hline 338.723 & 2.31 & 7.7 & $\mathrm{CH}_{3} \mathrm{OH}$ & $7(2)-6(2) \mathrm{E}$ & 338.7216 & 86.1 & blend \\
\hline 338.786 & 0.53 & 8.1 & ${ }^{34} \mathrm{SO}_{2}$ & $14(4,10)-14(3,11)$ & 338.7858 & 134 & \\
\hline 338.787 & 0.48 & 9 & ${ }^{34} \mathrm{SO}_{2}$ & $14(4,10)-14(3,11)$ & 338.7858 & 134 & \\
\hline 339.341 & 1.84 & 6.1 & $\mathrm{SO}$ & $3(3)-3(2)$ & 339.3415 & 25.5 & \\
\hline 339.342 & 1.59 & 6.7 & $\mathrm{SO}$ & $3(3)-3(2)$ & 339.3415 & 25.5 & \\
\hline 339.477 & 0.59 & 3.6 & $\mathrm{CN}$ & $3-22.52 .5-2.52 .5$ & 339.4759 & 16.3 & \\
\hline 339.478 & 0.37 & 4.9 & $\mathrm{CN}$ & $3-22.52 .5-2.52 .5$ & 339.4759 & 16.3 & \\
\hline 339.518 & 0.56 & 3.9 & $\mathrm{CN}$ & $3-22.53 .5-2.53 .5$ & 339.5167 & 16.3 & \\
\hline 339.518 & 0.72 & 5.2 & $\mathrm{CN}$ & $3-22.53 .5-2.53 .5$ & 339.5167 & 16.3 & \\
\hline 339.857 & 2.24 & 7.4 & ${ }^{34} \mathrm{SO}$ & $9(8)-8(7)$ & 339.8573 & 77.3 & sl-blend \\
\hline 339.857 & 2.29 & 7.4 & ${ }^{34} \mathrm{SO}$ & $9(8)-8(7)$ & 339.8573 & 77.3 & \\
\hline 340.008 & 1.19 & 6.1 & $\mathrm{CN}$ & $3-22.52 .5-1.52 .5$ & 340.0082 & 16.3 & sl-blend \\
\hline 340.009 & 1.09 & 5.8 & $\mathrm{CN}$ & $3-22.52 .5-1.52 .5$ & 340.0082 & 16.3 & sl-blend \\
\hline 340.021 & 1.33 & & $\mathrm{CN}$ & $3-22.51 .5-1.51 .5$ & 340.0196 & 16.3 & blend \\
\hline 340.033 & 4.23 & 10 & $\mathrm{CN}$ & $3-22.53 .5-1.52 .5$ & 340.0316 & 16.3 & sl-blend \\
\hline 340.052 & 1.24 & & $\mathrm{C}^{33} \mathrm{~S}$ & $7-6$ & 340.0527 & 65.3 & blend \\
\hline 340.247 & 5.20 & 8.7 & $\mathrm{CN}$ & $3-23.54 .5-2.53 .5$ & 340.2479 & 16.3 & sl-blend \\
\hline 340.248 & 5.65 & 7.1 & $\mathrm{CN}$ & $3-23.54 .5-2.53 .5$ & 340.2479 & 16.3 & blend \\
\hline 340.265 & 1.64 & & $\mathrm{CN}$ & $3-23.53 .5-2.53 .5$ & 340.265 & 16.3 & blend \\
\hline 340.265 & 1.52 & 7.8 & $\mathrm{CN}$ & $3-23.53 .5-2.53 .5$ & 340.265 & 16.3 & blend \\
\hline 340.316 & 0.87 & & $\mathrm{SO}_{2}$ & $28(2,26)-28(1,27)$ & 340.3165 & 392 & blend \\
\hline 340.317 & 0.80 & 6 & $\mathrm{SO}_{2}$ & $28(2,26)-28(1,27)$ & 340.3165 & 392 & sl-blend \\
\hline 340.317 & 0.69 & 7.4 & $\mathrm{SO}_{2}$ & $28(2,26)-28(1,27)$ & 340.3165 & 392 & \\
\hline 340.317 & 0.66 & 8.7 & $\mathrm{SO}_{2}$ & $28(2,26)-28(1,27)$ & 340.3165 & 392 & \\
\hline 340.414 & 4.78 & 10 & $\mathrm{SO}$ & $7(8)-6(7)$ & 340.7143 & 81.2 & \\
\hline 340.449 & 0.56 & 3.6 & OCS & $28-27$ & 340.4493 & 237 & \\
\hline 340.450 & 0.50 & 6 & OCS & $28-27$ & 340.4493 & 237 & \\
\hline 340.587 & 21.10 & 8.7 & ${ }^{13} \mathrm{CO}$ & $3-2$ & 330.588 & 31.7 & \\
\hline 340.632 & 0.65 & 4.8 & $\mathrm{HC}^{18} \mathrm{O}^{+}$ & $4-3$ & 340.6330 & 40.9 & \\
\hline 340.632 & 0.82 & 3.8 & $\mathrm{HC}^{18} \mathrm{O}^{+}$ & $4-3$ & 340.6330 & 40.9 & \\
\hline 340.715 & 5.13 & 10 & $\mathrm{SO}$ & $7(8)-6(7)$ & 340.7143 & 81.2 & \\
\hline 340.836 & 0.44 & 8.7 & ${ }^{33} \mathrm{SO}$ & $8(8)-7(7)$ & 340.8390 & & \\
\hline
\end{tabular}


Table 5. continued

\begin{tabular}{|c|c|c|c|c|c|c|c|}
\hline $\begin{array}{l}(\mathrm{obs}) \\
(\mathrm{GHz})\end{array}$ & $\begin{array}{l}T_{\mathrm{A}}^{*} \\
(\mathrm{~K})\end{array}$ & $\begin{array}{l}\Delta \nu_{1 / 2} \\
(\mathrm{MHz})\end{array}$ & Species & Transition & $\begin{array}{l}\nu \text { (rest) } \\
(\mathrm{GHz})\end{array}$ & $\begin{array}{c}E_{\mathrm{u}} / k \\
(\mathrm{~K})\end{array}$ & Notes \\
\hline 341.350 & 1.01 & 5.2 & $\mathrm{HCS}^{+}$ & $8-7$ & 341.3501 & 73.7 & \\
\hline 341.351 & 1.20 & & $\mathrm{HCS}^{+}$ & $8-7$ & 341.3501 & 73.7 & blend \\
\hline 341.416 & 1.97 & 6.4 & $\mathrm{CH}_{3} \mathrm{OH}$ & $7(1)-6(1) \mathrm{A}-$ & 341.4156 & 80.1 & \\
\hline 341.416 & 2.18 & 7.7 & $\mathrm{CH}_{3} \mathrm{OH}$ & $7(1)-6(1) \mathrm{A}-$ & 341.4156 & 80.1 & sl-blend \\
\hline 341.638 & 0.53 & 2.6 & $\mathrm{CH}_{3} \mathrm{CCH}$ & $20(4)-19(4)$ & 341.6371 & 287 & \\
\hline 341.683 & 1.15 & 4.8 & $\mathrm{CH}_{3} \mathrm{CCH}$ & $20(3)-19(3)$ & 341.6826 & 237 & \\
\hline 341.683 & 1.22 & 4.1 & $\mathrm{CH}_{3} \mathrm{CCH}$ & $20(3)-19(3)$ & 341.6826 & 237 & \\
\hline 341.716 & 1.07 & 5.2 & $\mathrm{CH}_{3} \mathrm{CCH}$ & $20(2)-19(2)$ & 341.7151 & 201 & \\
\hline 341.716 & 1.31 & 5.2 & $\mathrm{CH}_{3} \mathrm{CCH}$ & $20(2)-19(2)$ & 341.7151 & 201 & \\
\hline 341.735 & 1.64 & & $\mathrm{CH}_{3} \mathrm{CCH}$ & $20(1)-19(1)$ & 341.7346 & 179 & blend \\
\hline 341.736 & 1.68 & 4.6 & $\mathrm{CH}_{3} \mathrm{CCH}$ & $20(1)-19(1)$ & 341.7346 & 179 & sl-blend \\
\hline 341.742 & 1.71 & & $\mathrm{CH}_{3} \mathrm{CCH}$ & $20(0)-19(0)$ & 341.7411 & 172 & blend \\
\hline 341.742 & 1.73 & 5.5 & $\mathrm{CH}_{3} \mathrm{CCH}$ & $20(0)-19(0)$ & 341.7411 & 172 & sl-blend \\
\hline 342.208 & 0.63 & 5.3 & ${ }^{34} \mathrm{SO}_{2}$ & $5(3,3)-4(2,2)$ & 342.2089 & 35.1 & sl-blend \\
\hline 342.208 & 0.72 & 7.2 & ${ }^{34} \mathrm{SO}_{2}$ & $5(3,3)-4(2,2)$ & 342.2089 & 35.1 & \\
\hline 342.233 & 0.42 & 5.3 & ${ }^{34} \mathrm{SO}_{2}$ & $20(1,19)-19(2,18)$ & 342.2317 & 198 & \\
\hline 342.233 & 0.56 & 5.2 & ${ }^{34} \mathrm{SO}_{2}$ & $20(1,19)-19(2,18)$ & 342.2317 & 198 & \\
\hline 342.332 & 0.67 & 7.6 & ${ }^{34} \mathrm{SO}_{2}$ & $12(4,8)-12(3,9)$ & 342.3321 & 110 & sl-blend \\
\hline 342.333 & 0.51 & 7.5 & ${ }^{34} \mathrm{SO}_{2}$ & $12(4,8)-12(3,9)$ & 342.3321 & 110 & \\
\hline 342.882 & 12.01 & 12 & CS & $7-6$ & 342.8829 & 65.8 & self-abs \\
\hline 342.883 & 10.29 & 11 & CS & $7-6$ & 342.8829 & 65.8 & self-abs \\
\hline 342.947 & 1.09 & 9.3 & $\mathrm{H}_{2} \mathrm{CS}$ & $10(0,10)-9(0,9)$ & 342.9443 & 90.6 & \\
\hline 342.948 & 1.08 & 4.9 & $\mathrm{H}_{2} \mathrm{CS}$ & $10(0,10)-9(0,9)$ & 342.9443 & 90.6 & \\
\hline 343.088 & 0.70 & 2.3 & ${ }^{33} \mathrm{SO}$ & $8(9)-7(8)$ & 343.0860 & & \\
\hline 343.088 & 0.74 & 7.8 & ${ }^{33} \mathrm{SO}$ & $8(9)-7(8)$ & 343.0860 & & \\
\hline \multirow[t]{2}{*}{343.324} & 1.27 & 8.7 & $\mathrm{H}_{2} \mathrm{CS}$ & $10(2,9)-9(2,8)$ & 343.3198 & 143 & $*$ \\
\hline & & & $\mathrm{H}_{2}{ }^{13} \mathrm{CO}$ & $5(1,5)-4(1,4)$ & 343.3257 & 61.3 & \\
\hline \multirow[t]{2}{*}{343.324} & 1.24 & 6.8 & $\mathrm{H}_{2} \mathrm{CS}$ & $10(2,9)-9(2,8)$ & 343.3198 & 143 & * \\
\hline & & & $\mathrm{H}_{2}{ }^{13} \mathrm{CO}$ & $5(1,5)-4(1,4)$ & 343.3257 & 61.3 & \\
\hline 343.413 & 1.06 & 9.4 & $\mathrm{H}_{2} \mathrm{CS}$ & $10(3,8)-9(3,7)$ & 343.4077 & 209 & blend \\
\hline 343.413 & 1.15 & 6.1 & $\mathrm{H}_{2} \mathrm{CS}$ & $10(3,8)-9(3,7)$ & 343.4077 & 209 & blend \\
\hline 343.814 & 0.69 & 7.4 & $\mathrm{H}_{2} \mathrm{CS}$ & $10(2,8)-9(2,7)$ & 343.8109 & 143 & \\
\hline 343.815 & 0.81 & 4.1 & $\mathrm{H}_{2} \mathrm{CS}$ & $10(2,8)-9(2,7)$ & 343.8109 & 143 & \\
\hline 344.200 & 1.41 & 6.5 & $\mathrm{HC}^{15} \mathrm{~N}$ & $4-3$ & 344.2003 & 41.3 & \\
\hline 344.200 & 1.81 & 5.4 & $\mathrm{HC}^{15} \mathrm{~N}$ & $4-3$ & 344.2003 & 41.3 & \\
\hline 344.246 & 0.60 & 4.8 & ${ }^{34} \mathrm{SO}_{2}$ & $10(4,6)-10(3,7)$ & 344.2454 & 88.4 & \\
\hline 344.310 & 6.05 & 8.8 & $\mathrm{SO}$ & $8(8)-7(7)$ & 344.3107 & 87.5 & \\
\hline 344.311 & 6.07 & 11 & $\mathrm{SO}$ & $8(8)-7(7)$ & 344.3107 & 87.5 & \\
\hline \multirow[t]{2}{*}{344.969} & 0.69 & 7.7 & $\mathrm{SO}_{2}$ & $40(4,36)-40(3,37)$ v2 $=1$ & 344.9742 & 1550 & $*$ \\
\hline & & & $\mathrm{C}_{2} \mathrm{H}_{5} \mathrm{OH}$ & $21(0,21)-20(1,20)$ & 244.9676 & 241 & \\
\hline 344.986 & 0.55 & 9.7 & ${ }^{34} \mathrm{SO}_{2}$ & $15(4,12)-15(3,13)$ & 344.9876 & 148 & sl-blend \\
\hline 344.990 & 0.94 & 8.7 & ${ }^{34} \mathrm{SO}_{2}$ & $15(4,12)-15(3,13)$ & 344.9876 & 148 & sl-blend \\
\hline 344.997 & 0.60 & & ${ }^{34} \mathrm{SO}_{2}$ & $11(4,8)-11(3,9)$ & 344.9982 & 98.5 & blend \\
\hline 344.998 & 0.59 & 10 & ${ }^{34} \mathrm{SO}_{2}$ & $11(4,8)-11(3,9)$ & 344.9982 & 98.5 & sl-blend \\
\hline 345.149 & 0.44 & 6.4 & $\mathrm{SO}_{2}$ & $5(5,1)-6(4,2)$ & 345.1491 & 75.1 & \\
\hline 345.149 & 0.36 & 5.5 & $\mathrm{SO}_{2}$ & $5(5,1)-6(4,2)$ & 345.1491 & 75.1 & \\
\hline 345.169 & 0.57 & 6.1 & ${ }^{34} \mathrm{SO}_{2}$ & $8(4,4)-8(3,5)$ & 345.1688 & 70.9 & \\
\hline 345.169 & 0.73 & 7.4 & ${ }^{34} \mathrm{SO}_{2}$ & $8(4,4)-8(3,5)$ & 345.1688 & 70.9 & \\
\hline 345.285 & 0.63 & 7.5 & ${ }^{34} \mathrm{SO}_{2}$ & $9(4,6)-9(3,7)$ & 345.2857 & 79.2 & \\
\hline 345.287 & 0.53 & 6.2 & ${ }^{34} \mathrm{SO}_{2}$ & $9(4,6)-9(3,7)$ & 345.2857 & 79.2 & \\
\hline \multirow[t]{2}{*}{345.339} & 6.15 & 8.8 & $\mathrm{SO}_{2}$ & $13(2,12)-12(1,11)$ & 345.3385 & 93 & $*$ \\
\hline & & & $\mathrm{H}^{13} \mathrm{CN}$ & $4-3$ & 345.3398 & 41.3 & \\
\hline \multirow[t]{2}{*}{345.339} & 5.90 & 8.8 & $\mathrm{SO}_{2}$ & $13(2,12)-12(1,11)$ & 345.3385 & 93 & $*$ \\
\hline & & & $\mathrm{H}^{13} \mathrm{CN}$ & $4-3$ & 345.3398 & 41.3 & \\
\hline 345.520 & 0.58 & 4.8 & ${ }^{34} \mathrm{SO}_{2}$ & $7(4,4)-7(3,5)$ & 345.5198 & 63.6 & \\
\hline 345.553 & 0.522 & 4.2 & ${ }^{34} \mathrm{SO}_{2}$ & $6(4,2)-6(3,3)$ & 345.5532 & 57.2 & \\
\hline
\end{tabular}


Table 5. continued

\begin{tabular}{|c|c|c|c|c|c|c|c|}
\hline $\begin{array}{l}(\mathrm{obs}) \\
(\mathrm{GHz})\end{array}$ & $\begin{array}{l}T_{\mathrm{A}}^{*} \\
(\mathrm{~K}) \\
\end{array}$ & $\begin{array}{l}\Delta \nu_{1 / 2} \\
(\mathrm{MHz}) \\
\end{array}$ & Species & Transition & $\begin{array}{l}\nu \text { (rest) } \\
(\mathrm{GHz}) \\
\end{array}$ & $\begin{array}{c}E_{\mathrm{u}} / k \\
(\mathrm{~K})\end{array}$ & Notes \\
\hline 345.553 & 0.55 & 7.1 & ${ }^{34} \mathrm{SO}_{2}$ & $6(4,2)-6(3,3)$ & 345.5532 & 57.2 & \\
\hline 345.591 & 0.40 & 5.8 & ${ }^{34} \mathrm{SO}_{2}$ & $7(4,4)-7(3,5)$ & 345.5198 & 63.6 & sl-blend \\
\hline 345.608 & 1.00 & 6.1 & $\mathrm{HC}_{3} \mathrm{~N}$ & $38-37$ & 345.6090 & 323 & \\
\hline 345.609 & 0.97 & 6.1 & $\mathrm{HC}_{3} \mathrm{~N}$ & $38-37$ & 345.6090 & 323 & \\
\hline 345.651 & 0.54 & 5.8 & ${ }^{34} \mathrm{SO}_{2}$ & $5(4,2)-5(3,3)$ & 345.6514 & 51.7 & \\
\hline 345.651 & 0.50 & 2.6 & ${ }^{34} \mathrm{SO}_{2}$ & $5(4,2)-5(3,3)$ & 345.6514 & 51.7 & \\
\hline 345.794 & 26.74 & 45 & $\mathrm{CO}$ & $3-2$ & 345.796 & 33.2 & self-abs \\
\hline 345.794 & 25.11 & 44 & $\mathrm{CO}$ & $3-2$ & 345.796 & 33.2 & self-abs \\
\hline 345.929 & 0.56 & 10 & ${ }^{34} \mathrm{SO}_{2}$ & $17(4,14)-17(3,15)$ & 345.9294 & 179 & \\
\hline 346.528 & 7.06 & 13 & $\mathrm{SO}$ & $9(8)-8(7)$ & 346.5286 & 78.8 & \\
\hline 346.528 & 7.26 & 11 & $\mathrm{SO}$ & $9(8)-8(7)$ & 346.5286 & 78.8 & \\
\hline 346.652 & 2.68 & 10 & $\mathrm{SO}_{2}$ & $19(1,19)-18(0,18)$ & 346.6522 & 168 & \\
\hline 346.653 & 2.80 & 10 & $\mathrm{SO}_{2}$ & $19(1,19)-18(0,18)$ & 346.6522 & 168 & \\
\hline 346.999 & 4.54 & 6.1 & $\mathrm{H}^{13} \mathrm{CO}^{+}$ & $4-3$ & 346.9985 & 41.6 & \\
\hline 346.999 & 5.48 & 6.1 & $\mathrm{H}^{13} \mathrm{CO}^{+}$ & $4-3$ & 346.9985 & 41.6 & blend \\
\hline 347.323 & 1.23 & 10 & $\mathrm{SiO}$ & $8-7$ & 347.3306 & 75.0 & blend \\
\hline 347.332 & 1.56 & 10 & $\mathrm{SiO}$ & $8-7$ & 347.3306 & 75.0 & blend \\
\hline 347.740 & 0.52 & 6.2 & $\mathrm{U}$ & & & & $\mathrm{U}_{347.7430}$ (Schilke) \\
\hline 348.116 & 0.80 & 10 & ${ }^{34} \mathrm{SO}_{2}$ & $19(4,16)-19(3,17)$ & 348.1176 & 213 & \\
\hline 348.117 & 0.91 & 5.1 & ${ }^{34} \mathrm{SO}_{2}$ & $19(4,16)-19(3,17)$ & 348.1176 & 213 & \\
\hline 348.341 & 1.18 & 6.3 & $\mathrm{HN}^{13} \mathrm{C}$ & $4-3$ & 348.3403 & 41.8 & \\
\hline 348.341 & 1.56 & 6.3 & $\mathrm{HN}^{13} \mathrm{C}$ & $4-3$ & 348.3403 & 41.8 & \\
\hline 348.388 & 1.08 & 8.7 & $\mathrm{SO}_{2}$ & $24(2,22)-23(3,21)$ & 348.388 & 293 & \\
\hline 348.390 & 1.31 & 8.2 & $\mathrm{SO}_{2}$ & $24(2,22)-23(3,21)$ & 348.388 & 293 & \\
\hline 348.534 & 1.87 & 5.3 & $\mathrm{H}_{2} \mathrm{CS}$ & $10(1,9)-9(1,8)$ & 348.5321 & 105 & \\
\hline 348.535 & 2.11 & 4.3 & $\mathrm{H}_{2} \mathrm{CS}$ & $10(1,9)-9(1,8)$ & 348.5321 & 105 & \\
\hline 349.108 & 0.49 & 6.5 & $\mathrm{CH}_{3} \mathrm{OH}$ & $14(1)-14(0) \mathrm{A}+$ & 349.1070 & 260 & \\
\hline 349.339 & 7.63 & & $\mathrm{C}_{2} \mathrm{H}$ & $4.5-3.5$ & 349.3381 & 41.9 & blend \\
\hline 349.339 & 5.73 & 6 & $\mathrm{C}_{2} \mathrm{H}$ & $4.5-3.5$ & 349.3381 & 41.9 & sl-blend \\
\hline 349.392 & 1.18 & & $\mathrm{CH}_{3} \mathrm{CN}$ & $19(3)-18(3)$ & 349.393 & 232 & blend \\
\hline 349.393 & 1.39 & & $\mathrm{CH}_{3} \mathrm{CN}$ & $19(3)-18(3)$ & 349.393 & 232 & blend \\
\hline 349.400 & 4.76 & 6.5 & $\mathrm{C}_{2} \mathrm{H}$ & $3.5-2.5$ & 349.4006 & 41.9 & sl-blend \\
\hline 349.400 & 4.98 & 5.2 & $\mathrm{C}_{2} \mathrm{H}$ & $3.5-2.5$ & 349.4006 & 41.9 & sl-blend \\
\hline 349.401 & 4.23 & 6 & $\mathrm{C}_{2} \mathrm{H}$ & $3.5-2.5$ & 349.4006 & 41.9 & sl-blend \\
\hline 349.401 & 4.38 & 6.5 & $\mathrm{C}_{2} \mathrm{H}$ & $3.5-2.5$ & 349.4006 & 41.9 & sl-blend \\
\hline 349.427 & 1.07 & 3.2 & $\mathrm{CH}_{3} \mathrm{CN}$ & $19(2)-18(2)$ & 349.4266 & 196 & \\
\hline 349.428 & 0.69 & 7.4 & $\mathrm{CH}_{3} \mathrm{CN}$ & $19(2)-18(2)$ & 349.4266 & 196 & \\
\hline 349.447 & 1.12 & 5.5 & $\mathrm{CH}_{3} \mathrm{CN}$ & $19(1)-18(1)$ & 349.4467 & 175 & sl-blend \\
\hline 349.449 & 1.17 & & $\mathrm{CH}_{3} \mathrm{CN}$ & $19(1)-18(1)$ & 349.4467 & 175 & blend \\
\hline 349.453 & 0.85 & 5.1 & $\mathrm{CH}_{3} \mathrm{CN}$ & $19(0)-18(0)$ & 349.4534 & 168 & sl-blend \\
\hline 349.454 & 1.11 & & $\mathrm{CH}_{3} \mathrm{CN}$ & $19(0)-18(0)$ & 349.4534 & 168 & blend \\
\hline 349.604 & 0.40 & 5.8 & U & & & & \\
\hline \multirow[t]{2}{*}{350.689} & 2.25 & 7.5 & $\mathrm{CH}_{3} \mathrm{OH}$ & $4(0)-3(-1) E$ & 350.6877 & 35.1 & * \\
\hline & & & NO & $3.50 .5-2.50 .5$ & 350.6895 & 36.1 & $\mathrm{~h} /$ fines \\
\hline \multirow[t]{2}{*}{350.689} & 2.67 & 6.2 & $\mathrm{CH}_{3} \mathrm{OH}$ & $4(0)-3(-1) \mathrm{E}$ & 350.6877 & 35.1 & * \\
\hline & & & NO & 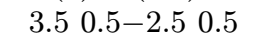 & 350.6895 & 36.1 & h/fines \\
\hline 351.044 & 1.24 & 5.5 & $\mathrm{NO}$ & $3.54 .5-2.53 .5$ & 351.0435 & 36.1 & sl-blend \\
\hline 351.044 & 1.37 & 4.9 & $\mathrm{NO}$ & $3.54 .5-2.53 .5$ & 351.0435 & 36.1 & sl-blend \\
\hline 351.052 & 1.63 & 5.2 & $\mathrm{NO}$ & $3.53 .5-2.52 .5$ & 351.0517 & 36.1 & sl-blend \\
\hline 351.052 & 1.40 & 6.2 & $\mathrm{NO}$ & $3.53 .5-2.52 .5$ & 351.0517 & 36.1 & sl-blend \\
\hline 351.257 & 2.39 & 10 & $\mathrm{SO}_{2}$ & $5(3,3)-4(2,2)$ & 351.2572 & 35.9 & \\
\hline 351.257 & 2.66 & 9.1 & $\mathrm{SO}_{2}$ & $5(3,3)-4(2,2)$ & 351.2572 & 35.9 & \\
\hline
\end{tabular}


Table 5. continued

\begin{tabular}{|c|c|c|c|c|c|c|c|}
\hline $\begin{array}{l}\nu(\mathrm{obs}) \\
(\mathrm{GHz})\end{array}$ & $\begin{array}{c}T_{\mathrm{A}}^{*} \\
(\mathrm{~K})\end{array}$ & $\begin{array}{l}\Delta \nu_{1 / 2} \\
(\mathrm{MHz})\end{array}$ & Species & Transition & $\begin{array}{l}\text { (rest) } \\
(\mathrm{GHz})\end{array}$ & $\begin{array}{c}E_{\mathrm{u}} / k \\
(\mathrm{~K})\end{array}$ & Notes \\
\hline 351.633 & 0.55 & 7.5 & $\mathrm{HNCO}$ & $16(0,16)-15(0,15)$ & 351.6335 & 143 & $\mathrm{~h} /$ fine blend \\
\hline 351.634 & 0.98 & 5.5 & $\mathrm{HNCO}$ & $16(0,16)-15(0,15)$ & 351.6335 & 143 & $\mathrm{~h} /$ fine blend \\
\hline 351.769 & 9.47 & & $\mathrm{H}_{2} \mathrm{CO}$ & $5(1,5)-4(1,4)$ & 351.7686 & 62.5 & blend \\
\hline 351.769 & 9.16 & 8.7 & $\mathrm{H}_{2} \mathrm{CO}$ & $5(1,5)-4(1,4)$ & 351.7686 & 62.5 & sl-blend \\
\hline 351.874 & 1.79 & 8.8 & $\mathrm{SO}_{2}$ & $14(4,10)-14(3,11)$ & 351.8739 & 136 & \\
\hline 351.874 & 2.06 & 9.1 & $\mathrm{SO}_{2}$ & $14(4,10)-14(3,11)$ & 351.8739 & 136 & \\
\hline 352.599 & 0.89 & 5.5 & OCS & $29-28$ & 352.5996 & 254 & \\
\hline 352.600 & 0.62 & 7.1 & OCS & $29-28$ & 352.5996 & 254 & \\
\hline 354.503 & 14.34 & 14 & $\mathrm{HCN}$ & $4-3$ & 354.5055 & 42.5 & sl-blend \\
\hline 354.503 & 15.44 & 15 & $\mathrm{HCN}$ & $4-3$ & 354.5055 & 42.5 & sl-blend \\
\hline 354.597 & 1.00 & 6.5 & $\mathrm{U}$ & & & & sba \\
\hline 354.697 & 1.02 & 7.8 & $\mathrm{HC}_{3} \mathrm{~N}$ & $39-38$ & 354.6975 & 341 & \\
\hline 354.697 & 0.89 & 3.8 & $\mathrm{HC}_{3} \mathrm{~N}$ & $39-38$ & 354.6975 & 341 & \\
\hline 354.697 & 0.81 & 7.5 & $\mathrm{HC}_{3} \mathrm{~N}$ & $39-38$ & 354.6975 & 341 & \\
\hline 354.698 & 0.90 & 5.5 & $\mathrm{HC}_{3} \mathrm{~N}$ & $39-38$ & 354.6975 & 341 & \\
\hline 355.046 & 1.72 & 8.5 & $\mathrm{SO}_{2}$ & $12(4,8)-13(3,9)$ & 355.0456 & 111 & \\
\hline 355.046 & 1.87 & 10 & $\mathrm{SO}_{2}$ & $12(4,8)-13(3,9)$ & 355.0456 & 111 & sl-blend \\
\hline 355.570 & 0.52 & 7.4 & $\mathrm{~S}^{18} \mathrm{O}$ & $9(8)-8(7)$ & 355.5736 & 93.1 & \\
\hline 355.571 & 0.41 & 7.7 & $\mathrm{~S}^{18} \mathrm{O}$ & $9(8)-8(7)$ & 355.5736 & 93.1 & \\
\hline 355.603 & 0.78 & 6 & $\mathrm{CH}_{3} \mathrm{OH}$ & $13(0)-12(1) \mathrm{A}+$ & 355.6030 & 211 & \\
\hline 355.604 & 0.81 & 6.1 & $\mathrm{CH}_{3} \mathrm{OH}$ & $13(0)-12(1) \mathrm{A}+$ & 355.6030 & 211 & \\
\hline 356.008 & 0.38 & 6.1 & $\mathrm{CH}_{3} \mathrm{OH}$ & $15(1)-15(0) \mathrm{A}-, \mathrm{A}+$ & 356.0066 & 296 & \\
\hline 356.041 & 0.67 & 6.1 & $\mathrm{SO}_{2}$ & $15(7,9)-16(6,10)$ & 356.0407 & 230 & \\
\hline 356.042 & 0.64 & 10 & $\mathrm{SO}_{2}$ & $15(7,9)-16(6,10)$ & 356.0407 & 230 & \\
\hline 356.223 & 0.27 & 8.7 & ${ }^{34} \mathrm{SO}_{2}$ & $25(3,23)-25(2,14)$ & 356.2224 & 320 & \\
\hline 356.733 & 22.41 & 12 & $\mathrm{HCO}^{+}$ & $4-3$ & 356.7342 & 42.8 & self-abs \\
\hline 356.733 & 21.61 & 13 & $\mathrm{HCO}^{+}$ & $4-3$ & 356.7342 & 42.8 & self-abs \\
\hline 357.165 & 1.73 & 9.1 & $\mathrm{SO}_{2}$ & $13(4,10)-13(3,11)$ & 357.1654 & 123 & sl-blend \\
\hline 357.167 & 3.00 & & $\mathrm{SO}_{2}$ & $13(4,10)-13(3,11)$ & 357.1654 & 123 & blend \\
\hline 357.241 & 2.19 & 10 & $\mathrm{SO}_{2}$ & $15(4,12)-15(3,13)$ & 357.2412 & 150 & sl-blend \\
\hline 357.387 & 1.62 & 10 & $\mathrm{SO}_{2}$ & $11(4,8)-11(3,9)$ & 357.3876 & 100 & \\
\hline 357.387 & 1.72 & 10 & $\mathrm{SO}_{2}$ & $11(4,8)-11(3,9)$ & 357.3876 & 100 & \\
\hline 357.581 & 1.45 & 10 & $\mathrm{SO}_{2}$ & $8(4,4)-8(3,5)$ & 357.5815 & 72.4 & \\
\hline 357.582 & 1.56 & 8 & $\mathrm{SO}_{2}$ & $8(4,4)-8(3,5)$ & 357.5815 & 72.4 & \\
\hline 357.660 & 0.74 & & $\mathrm{U}$ & & & & sba blend \\
\hline 357.672 & 1.97 & 8.7 & $\mathrm{SO}_{2}$ & $9(4,6)-9(3,7)$ & 357.6719 & 80.6 & \\
\hline 357.672 & 1.95 & 8.4 & $\mathrm{SO}_{2}$ & $9(4,6)-9(3,7)$ & 357.6719 & 80.6 & \\
\hline 357.892 & 1.79 & 10 & $\mathrm{SO}_{2}$ & $7(4,4)-7(3,5)$ & 357.8925 & 65 & \\
\hline 357.893 & 1.90 & 10 & $\mathrm{SO}_{2}$ & $7(4,4)-7(3,5)$ & 357.8925 & 65 & \\
\hline 357.926 & 1.81 & 10 & $\mathrm{SO}_{2}$ & $6(4,2)-6(3,3)$ & 357.9259 & 58.6 & \\
\hline 357.927 & 1.89 & 9.7 & $\mathrm{SO}_{2}$ & $6(4,2)-6(3,3)$ & 357.9259 & 58.6 & \\
\hline 357.963 & 1.55 & 10 & $\mathrm{SO}_{2}$ & $17(4,14)-17(3,15)$ & 357.9629 & 180 & \\
\hline 357.963 & 1.68 & 8.9 & $\mathrm{SO}_{2}$ & $17(4,14)-17(3,15)$ & 357.9629 & 180 & \\
\hline 358.013 & 1.53 & 8.9 & $\mathrm{SO}_{2}$ & $5(4,2)-5(3,3)$ & 358.0132 & 53.1 & \\
\hline 358.013 & 1.68 & 7.7 & $\mathrm{SO}_{2}$ & $5(4,2)-5(3,3)$ & 358.0132 & 53.1 & \\
\hline 358.039 & 1.34 & 10 & $\mathrm{SO}_{2}$ & $4(4,0)-4(3,1)$ & 358.038 & 48.5 & sl-blend \\
\hline 358.039 & 1.42 & 8.9 & $\mathrm{SO}_{2}$ & $4(4,0)-4(3,1)$ & 358.038 & 48.5 & \\
\hline
\end{tabular}


Table 5. continued

\begin{tabular}{|c|c|c|c|c|c|c|c|}
\hline $\begin{array}{l}\nu(\mathrm{obs}) \\
(\mathrm{GHz})\end{array}$ & $\begin{array}{l}T_{\mathrm{A}}^{*} \\
(\mathrm{~K})\end{array}$ & $\begin{array}{l}\Delta \nu_{1 / 2} \\
(\mathrm{MHz})\end{array}$ & Species & Transition & $\begin{array}{l}\text { (rest) } \\
(\mathrm{GHz})\end{array}$ & $\begin{array}{c}E_{\mathrm{u}} / k \\
(\mathrm{~K})\end{array}$ & Notes \\
\hline 358.216 & 2.56 & 9.7 & $\mathrm{SO}_{2}$ & $20(0,20)-19(1,19)$ & 358.2157 & 185 & \\
\hline 358.216 & 2.70 & 10 & $\mathrm{SO}_{2}$ & $20(0,20)-19(1,19)$ & 358.2157 & 185 & \\
\hline 358.348 & 0.33 & 8.4 & ${ }^{34} \mathrm{SO}_{2}$ & $23(4,20)-23(3,21)$ & 358.3473 & 292 & \\
\hline 358.605 & 1.57 & 8.9 & $\mathrm{CH}_{3} \mathrm{OH}$ & $4(1)-3(0) \mathrm{E}$ & 358.6058 & 43.1 & \\
\hline 358.606 & 1.74 & 6.8 & $\mathrm{CH}_{3} \mathrm{OH}$ & $4(1)-3(0) E$ & 358.6058 & 43.1 & \\
\hline \multirow[t]{2}{*}{358.646} & 0.49 & 5.8 & $\mathrm{CH}_{3} \mathrm{CCH}$ & $21(5)-20(5)$ & 358.6475 & 369 & $*$ \\
\hline & & & $\mathrm{S}^{18} \mathrm{O}$ & $9(8)-8(8)$ & 358.6488 & 99.3 & \\
\hline \multirow[t]{2}{*}{358.647} & 0.41 & 8.9 & $\mathrm{CH}_{3} \mathrm{CCH}$ & $21(5)-20(5)$ & 358.6475 & 369 & * \\
\hline & & & $\mathrm{S}^{18} \mathrm{O}$ & $9(8)-8(8)$ & 358.6488 & 99.3 & \\
\hline 358.710 & 0.25 & 5.5 & $\mathrm{CH}_{3} \mathrm{CCH}$ & $21(4)-20(4)$ & 358.7089 & 305 & \\
\hline 358.756 & 0.66 & 7.8 & $\mathrm{CH}_{3} \mathrm{CCH}$ & $21(3)-20(3)$ & 358.7566 & 254 & \\
\hline 358.757 & 0.89 & 6.1 & $\mathrm{CH}_{3} \mathrm{CCH}$ & $21(3)-20(3)$ & 358.7566 & 254 & \\
\hline 358.791 & 0.69 & 6.2 & $\mathrm{CH}_{3} \mathrm{CCH}$ & $21(2)-20(2)$ & 358.7908 & 218 & \\
\hline 358.791 & 0.64 & 7.8 & $\mathrm{CH}_{3} \mathrm{CCH}$ & $21(2)-20(2)$ & 358.7908 & 218 & \\
\hline 358.812 & 0.76 & & $\mathrm{CH}_{3} \mathrm{CCH}$ & $21(1)-20(1)$ & 358.8112 & 197 & blend \\
\hline 358.812 & 0.99 & 4.9 & $\mathrm{CH}_{3} \mathrm{CCH}$ & $21(1)-20(1)$ & 358.8112 & 197 & sl-blend \\
\hline 358.819 & 0.87 & 4.8 & $\mathrm{CH}_{3} \mathrm{CCH}$ & $21(0)-20(0)$ & 358.8181 & 189 & sl-blend \\
\hline 358.819 & 0.58 & & $\mathrm{CH}_{3} \mathrm{CCH}$ & $21(0)-20(0)$ & 358.8181 & 189 & blend \\
\hline 358.988 & 0.66 & 6.8 & ${ }^{34} \mathrm{SO}_{2}$ & $15(2,14)-14(1,13)$ & 358.9880 & 119 & \\
\hline 358.989 & 0.61 & 7.1 & ${ }^{34} \mathrm{SO}_{2}$ & $15(2,14)-14(1,13)$ & 358.9880 & 119 & \\
\hline 359.771 & 1.58 & 7.7 & $\mathrm{SO}_{2}$ & $19(4,16)-19(3,17)$ & 359.7707 & 214 & \\
\hline 359.772 & 1.10 & 11 & $\mathrm{SO}_{2}$ & $19(4,16)-19(3,17)$ & 359.7707 & 214 & \\
\hline
\end{tabular}

